\title{
Usuarios 2.0 de la información audiovisual y textual
}

Juan José Calva González

COORDINADOR

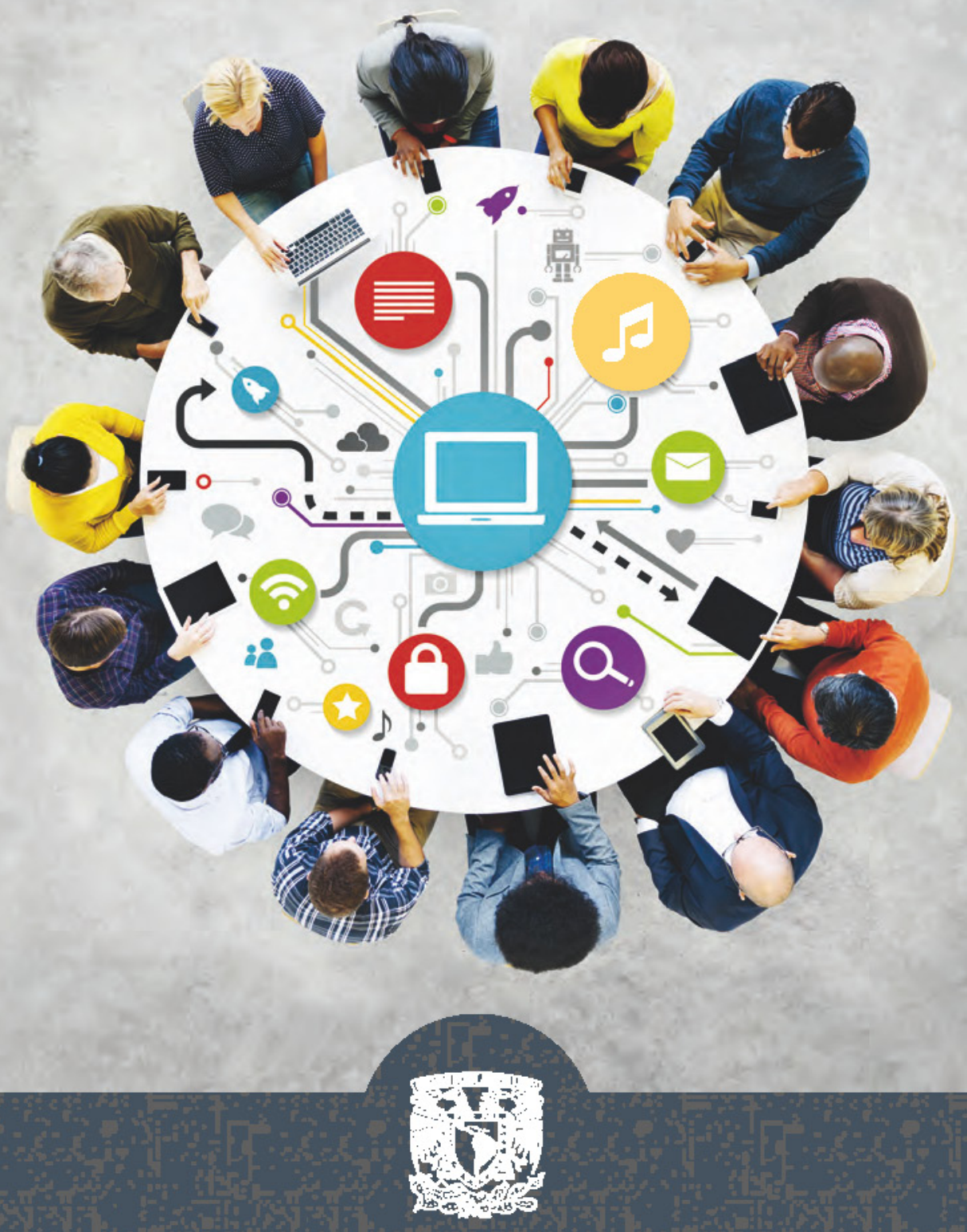




\section{La presente obra está bajo una licencia de:}

\section{http://creativecommons.org/licenses/by-nc-sa/3.0/deed.es MX}

\section{Atribución-No Comercial-Licenciamiento Reciproco 3.0 Unported}

Eres libre de:

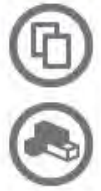

copiar, distribuir y comunicar públicamente la obra

hacer obras derivadas

Bajo las condiciones siguientes:

Atribución - Debes reconocer la autoría de la obra en los términos

especificados por el propio autor o licenciante.

No comercial - No puedes utilizar esta obra para fines comerciales.

Licenciamiento Recíproco - Si alteras, transformas o creas una obra a

partir de esta obra, solo podrás distribuir la obra resultante bajo una licencia

igual a ésta.

\section{Esto es un resumen fácilmente legible del: texto legal (de la licencia completa)}

En los casos que sea usada la presente obra, deben respetarse los términos especificados en esta licencia.
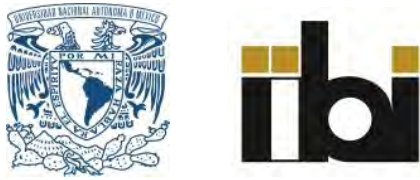
Usuarios 2.0 de la información audiovisual y textual 
Instituto de Investigaciones Bibliotecológicas y de la Información 


\title{
Usuarios 2.0 de la información audiovisual y textual
}

\author{
Coordinador \\ Juan José Calva González
}

Universidad Nacional Autónoma de México 2017 
Z674.75 Usuarios 2.0 de la información audiovisual y textual / W67U78 coordinador Juan José Calva González.-- México : UNAM, Instituto de Investigaciones Bibliotecológicas y de la Información, 2017.

\section{xi, 103 p. -- (Usuarios de la información) ISBN: 978-607-02-9246-0}

Web 2.0 -- Usuarios -- Recuperación de Información Usuarios -- Internet -- Acceso a la Información I. Calva González, Juan José, coordinador II. ser.

Diseño de portada: Mario Ocampo Chávez

Imagen: (๑) Rawpixel.com/Fotolia

Primera edición, 2017

D.R. () UNIVERSIDAD NACIONAL AUTÓNOMA DE MÉXICO

Ciudad Universitaria, 04510, México D.F.

Impreso y hecho en México

ISBN: 978-607-02-9246-0 


\section{Contenido}

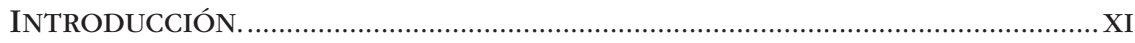

Juan José Calva González

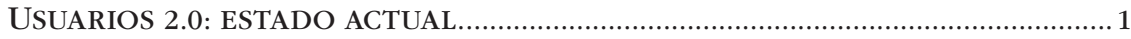

Luisa Orera Orera

USUARIOS 2.0: DEFINICIÓN.

7

Juan José Calva González

USUARIOS 2.0: CARACTERÍSTICAS Y TIPOLOGÍA

Isabel Villaseñor Rodríguez

RELACIÓN DE USUARIOS 2.0 CON DIFERENTES REDES

SOCIALES PARA LA RECUPERACIÓN E INTERCAMBIO

DE INFORMACIÓN AUDIOVISUAL Y TEXTUAL.

.25

Juan José Calva González

INTERACTUACIÓN 2.0 ENTRE MEDIOS DE COMUNICACIÓN

TELEVISIVOS Y USUARIOS: USO DE REDES SOCIALES

EN MEDIOS ESPAÑOLES Y MEXICANOS.

Jorge Caldera Serrano

DIFICULTADES A LAS QUE SE ENFRENTAN

LAS COMUNIDADES INDÍGENAS

PARA SER CONSIDERADAS USUARIAS 2.0.

César Augusto Ramírez Velázquez

RELACIÓN DEL USUARIO 2.0

CON LAS BIBLIOTECAS UNIVERSITARIAS 83

Luisa Orera Orera

EL PERFIL DEL USUARIO 2.0 DE LA INFORMACIÓN

AUDIOVISUAL Y TEXTUAL: ANÁLISIS Y DISCUSIÓN 101

Isabel Villaseñor Rodríguez

Juan José Calva González 
Este proyecto "Usuarios 2.0 de la información audiovisual y textual" fue apoyado por el Programa de Apoyo a Proyectos de Investigación e Innovación Tecnológica (PAPIIT) con el numero IN 401712 por parte de la Dirección General de Asuntos del Personal Académico de la Universidad Nacional Autónoma de México. Asimismo, es importante mencionar la amplia participación y colaboración como investigadora corresponsable de España en este proyecto de la Dra. Isabel Villaseñor Rodríguez, Profesora Titular de la Universidad Complutense de Madrid, para la parte correspondiente al seguimiento de las investigaciones en ese país y que formaron parte de este proyecto, siendo los otros participantes: la Dra. Luisa Orera Orera de la Universidad de Zaragoza y el Dr. Jorge Calera Serrano de la Universidad de Extremadura. También quiero agradecer la participación del Dr. César Augusto Ramírez Velázquez, investigador del Instituto de Investigaciones Bibliotecológicas y de la Información de la UNAM, por su aportación con sus investigaciones a este proyecto. Cabe mencionar también la participación de los becarios con que contó este proyecto y los resultados de sus investigaciones con las cuales fue posible llevarlo a cabo, y quienes a la vez obtuvieron sus respectivos títulos y grado: Lic. Edgar Guzmán Prieto, Lic. Cinthya Berenice Sánchez Flores, Lic. José Mauricio Anaya Rivas, Lic. Iván Santiago Sales Ortega, Lic. Mariana Méndez Vergara y la Lic. Olivia Nayely Torres Piñón y el Mtro. Luis Alberto Fuentes Gatica. 


\section{Introducción}

$\mathrm{E}$ 1 usuario de la biblioteca tradicional lugar donde se encuentra el material impreso y que comúnmente son libros y revistas, suele ser un objeto de investigación de la bibliotecología, la documentación y en general de las ciencias de la información. Así fue durante varias décadas del siglo pasado y lo ha sido durante la aparición de las tecnologías de la información y la comunicación, y entre ellas la llegada de Internet, la web y actualmente la Web 2.0, las cuales le han dado una perspectiva diferente al estudio de los usuarios de la información, ya que el acceso a los recursos de información electrónica, como el libro electrónico y la revista electrónica, llevó a los usuarios a presentar un comportamiento informativo diferente al de sus predecesores. Y también la llegada de las redes sociales, como una de las herramientas de la Web 2.0, y su particular filosofía de compartir la información y de participar en su creación directamente, involucra una participación más amplia del usuario, ya no sólo como consumidor de información sino como creador de ella (véanse las wikis, y sobre todo la Wikipedia como ejemplo más significativo). Todo ello lleva a que ese objeto de investigación, el usuario de la información, ahora en un ambiente Web 2.0, deba ser mejor estudiado, ya que el acceso a Internet de forma inalámbrica es 
casi posible desde cualquier parte del planeta vía una computadora, una tableta o un teléfono celular.

Las tecnologías (en un ambiente Web 2.0) y las nuevas formas de buscar la información, localizarla, obtenerla y compartirla, llevan al planteamiento de muchas diferentes cuestiones: ¿qué son las redes sociales?, ¿cuál es su tipología, las características y las herramientas que utilizan?, ¿cuál es el impacto de la Web 2.0 en cuanto a la visibilidad de la información académica cuando buscan dicha información los usuarios?, ¿qué herramientas y recursos tiene la Web 2.0 para ser explotados en beneficio de los grandes sectores sociales que pueden tener acceso a la información académica producto de la investigación y la docencia?, ¿cuál es el perfil de los usuarios de la información que utilizan las redes sociales para sus búsquedas informativas?, ¿qué tipo de información circula en las redes sociales que son utilizadas por los usuarios de las mismas?, ¿qué factores motivan a los usuarios a utilizar las redes sociales, tanto las académicas como las que no lo son? ¿Las bibliotecas y centros de documentación forman parte de las redes sociales?, pero si esto es así, ¿cuál es el rol que estas instituciones desempeñan? ¿Qué papel juegan los usuarios de las bibliotecas en relación con los centros de documentación que pertenecen a alguna red social académica o de investigación o de algún otro tipo? ¿Cuáles son las diferencias existentes entre los usuarios de las bibliotecas y centros de documentación y los usuarios de las redes sociales?, y ¿la información contenida en las bibliotecas y centros de documentación llega a los usuarios a través de esas redes sociales?

Las inquietantes preguntas anteriores son sólo algunas de las que se pueden establecer y unas cuantas de ellas son abordadas en los capítulos que contiene esta obra. Pero este tipo de temas no se agotan con una sola investigación debido al cambio constante, no sólo de la tecnología sino también en la forma en que está siendo utilizada por sectores sociales cada vez más amplios, en tanto que, como se mencionó antes, cada vez es más fácil el acceso a Internet desde cualquier dispositivo móvil y casi desde cualquier parte del mundo. Por lo anterior, esta obra presenta a los usuarios de la información un ambiente Web 2.0 desde varias perspectivas, con la 
intención de lograr un acercamiento a algunas de las preguntas antes planteadas. Así también se expone el comportamiento de sujetos que van desde alumnos de nivel básico hasta aquellos de nivel superior, y también el de las comunidades indígenas que son un sector social que debe ser atendido y que tiene necesidades particulares de información que deben satisfacer. Nos interesa también el comportamiento indígena respecto a las tecnologías de la información y la comunicación, sobre todo con la Web 2.0 y el uso de las redes sociales, donde el usuario ya no sólo es consumidor sino también productor de información, en un ambiente de participación en el que ésta se comparte. También se busca saber cómo el ambiente ha permeado los medios de comunicación y cómo se comportan los usuarios dentro de un ambiente Web 2.0. Además se averiguará cómo las bibliotecas enfrentan la utilización de este nuevo ambiente web y cómo pueden comunicarse con su comunidad de usuarios a través del otorgamiento de sus servicios en tal ambiente, ya que al ser unidades de información, no pueden quedarse al margen de estos acontecimientos.

La riqueza de los capítulos que contiene este libro no sólo va a tratar de responder algunas preguntas sobre el Usuario 2.0 y su comportamiento en los diferentes recursos de información y las redes sociales, sino que abrirá nuevas líneas de investigación, sobre todo con miras a establecer lazos y/o relaciones entre los servicios de información y los Usuarios 2.0 utilizando las mismas herramientas que provee la propia Web 2.0. 


\title{
Usuarios 2.0: estado actual
}

\author{
LUISA Orera Orera \\ Universidad de Zaragoza
}

\section{ANTECEDENTES}

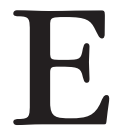

1 origen del concepto Web 2.0 hay que contextualizarlo en el periodo en que se desarrollaron las denominadas empresas puntocom y la posterior burbuja tecnológica o burbuja puntocom, términos popularizados por la prensa económica y que han pasado a formar parte de nuestras vidas.

El término puntocom es la traducción del término dotcom. Vélez Barreiro ${ }^{1}$ dice que es un término reciente que fue usado por primera vez en 1999, en inglés, en The Times y un año más tarde, en español, en Expansión. Se usa para referirse a empresas que desarrollan su actividad a través de Internet y que disponen de un sitio web con una dirección que frecuentemente acaba en .com, un dominio barato, fácil de obtener y de recordar. Por ello, estas empresas comenzaron a expandirse y a conocerse como empresas.com.

Su expansión tuvo lugar entre los años 1995 y 2001 y revolucionaron el mundo de los negocios. Muchas veces eran empresas fundadas por jóvenes emprendedores que sacaban una oferta pú-

1 M. Vélez Barreiro, La popularización del lenguaje español en la economía, la empresa y las finanzas. 
blica de acciones en bolsa y obtenían grandes beneficios. En 2001 estalló la llamada burbuja puntocom y muchas de estas empresas se vinieron abajo.

El concepto Web 2.0 fue creado por O'Reilly en 2004, y nació en una sesión de "brainstorming" o tormenta de ideas, organizada por dos empresas que no habían sido arrastradas por la crisis, O'Reilly y MediaLive. Pensaron que aquellas empresas que habían sobrevivido a la burbuja debían reunir una serie de características que no tenían las que habían fracasado. Buscaron dichas características y llamaron al resultado Web 2.0. ${ }^{2}$

Año y medio después del nacimiento del concepto Web 2.0, el término que lo identificaba había arraigado, y había ya más de 9,5 millones de menciones en Google. Actualmente, su creador "considera que el concepto 'Web 2.0', que él mismo acuñó para definir una web más dinámica y participativa, ha envejecido y quedado obsoleto para explicar una realidad tecnológica en la que se imponen la movilidad y la computación en la nube". 3

La Web 2.0 ha sido definida en numerosos estudios. Monsoriu ${ }^{4}$ se refiere a ella como: "[...]una segunda generación de contenidos web creados por los propios usuarios de Internet y puestos a disposición de los demás por medio de herramientas que permiten compartir contenidos en la red como son las wikis, blogs o las redes y los medios sociales".

Margaix Arnal $^{5}$ ha subrayado sus principales características:

1. Nace de la observación y no de un replanteamiento de los servicios de Internet. Antes de formularse el concepto, ya existían servicios que podían calificarse como Web 2.0.

2 T O'Reilly. What is Web 2.0: Design Patterns and Business Models for the Next Generation of Software.

3 ELMUNDO.es., El creador del concepto 'Web 2.0' asegura que a pesar de su éxito 'está obsoleto'.

4 Monsoriu, Diccionario Web 2.0., p. 156.

5 D. Margaix, "Conceptos de Web 2.0 y Biblioteca 2.0: origen, definiciones y retos para las bibliotecas actuales”. El profesional de la información, p. 96. 
2. Surge en el mundo empresarial y tiene una marcada impronta tecnológica y de comercialización (marketing).

3. No hay una característica clave para identificar un servicio web como 2.0, sino que existen varias que pueden cumplirse en mayor o menor medida, pero es difícil encontrarlas todas simultáneamente.

Poniendo el enfasis en la tecnología y siguiendo la idea dada por O'Reilly, puede decirse que las aplicaciones 2.0 son aquellas que sacan partido de las ventajas intrínsecas de la web y ofrecen un servicio continuamente actualizado que mejora cuanto más gente lo usa, utilizando y remezclando los datos de múltiples recursos, incluyendo los usuarios individuales y a la vez ofreciendo los datos y servicios para ser utilizados por otros, lo cual fue creando una arquitectura de participación en la red, que fue más allá que la página Web 1.0 para ofrecerles a los usuarios experiencias cada vez más ricas.

Sin embargo, no es la tecnología lo que más resalta en la Web 2.0, sino los principios de compartir, reutilizar, mejorar continuamente, considerando al usuario como fuente de información y confianza, y aprovechando la inteligencia colectiva, etc. De esta manera, la auténtica revolución se produjo con el cambio de consideración de los usuarios, los cuales pasaron de ser consumidores de información a ser agentes participativos en la elaboración y gestión de contenidos. El uso de la web se está orientando a la creación e interacción de redes sociales que pueden proporcionar contenidos de forma dinámica, y crear webs interactivas y visuales. En definitiva, los sitios Web 2.0 actuarían más como puntos de encuentro o webs dependientes de usuarios que como webs tradicionales.

Con la Web 2.0 se promociona y cultiva la inteligencia colectiva mediante la puesta en común de las aportaciones de los usuarios de redes que pueden vivir muy alejados entre sí. Es un medio democrático en el que todos los usuarios pueden manifestar sus opiniones y poner a disposición de otros su conocimiento.

Con estas características, es indudable que la Web 2.0 ha supuesto una auténtica revolución en el mundo de los negocios, de 
la información, la comunicación, la investigación, la educación, la medicina, etc.

Pero este culto a la web 2.0 o Web social, como también se le llama, que se ha hecho omnipresente en nuestras vidas y que no para de generar publicaciones más o menos reflexivas y repetitivas, no debe ocultar algunas incertidumbres o amenazas. García Markina ${ }^{6}$ ha señalado las siguientes: contenidos escritos por amateurs. Riesgos jurídicos, abuso de las acciones de compartir y re-compartir; provoca adicción, se deja de lado el diseño, las aplicaciones web son más lentas que las aplicaciones de escritorio; hay infinidad de problemas relacionados con la privacidad; se da una masificación de la publicidad en Internet, y hay espionaje de Estado. A esto podríamos añadir: la inflación de información, que es difícil de controlar; la falta de tiempo para reflexionar sobre la información que recibimos; la falsa ilusión de tener relación con muchas personas, cuando muchas veces estamos solos.

\section{Aplicaciones 2.0}

Las aplicaciones de la Web 2.0 son numerosísimas y están sometidas a un cambio permanente. Cobo Romaní, ${ }^{7}$ tras señalar las dificultades que entraña clasificar los recursos 2.0, distingue cuatro grupos:

1. Social Networking (Interconexión social). Herramientas que permiten crear comunidades, redes sociales, que intercambian contenidos directamente, sin necesidad de intermediarios. Los ejemplos son numerosísimos: Facebook, Tuenti, LinkedIn, etcétera.

2. Contenidos. Aplicaciones que facilitan la lectura y la escritura en línea, su distribución e intercambio. Las más des-

6 M. García Markina, En contra de la web 2.o.

7 C. Cobo Romaní, Capítulo 3. "Mapa de aplicaciones. Una taxonomía comentada”. En Cobo Romaní, Cristóbal; Pardo Kuklinski, Hugo. Planeta web 2.0. Inteligencia colectiva o medios fast food, pp. 161-183. 
tacadas son los blogs y las wikis, cuyo paradigma en este último caso es, sin duda, Wikipedia. Pero a estas aplicaciones habría que añadir otras como los procesadores de textos y hojas de cálculo en línea; plataformas para editar y compartir fotografías, como Flickr o Picasa; otras para compartir vídeos, como You Tube; o para presentaciones, tipo PowerPoint, como SlideShare.

3. Organización social e inteligente de la información. Bajo este epígrafe, se agrupan todas aquellas herramientas que ayudan a organizar y, por lo tanto, a buscar e identificar contenidos existentes en Internet. En este grupo se sitúan las aplicaciones para sindicar contenidos; los marcadores sociales de favoritos y las nubes de tags.

4. Aplicaciones y servicios (mashups). Dentro de este grupo se sitúan los webtops, páginas web que ofrecen las funciones de un escritorio pero de forma virtual, como Netvibes; plataformas que posibilitan el almacenamiento remoto de documentos y archivos de forma gratuita o mediante pago; o reproductores y agregadores de música.

\section{BIBLIOGRAFÍA}

Cobo Romaní, Cristóbal (2007), Capítulo 3. "Mapa de aplicaciones. Una taxonomía comentada". En Cobo Romaní, Cristóbal; Pardo Kuklinski, Hugo. Planeta Web 2.O. Inteligencia colectiva o medios fast food. [en línea]. Barcelona; México D.F.: Grup de Recerca d'Interaccions Digitals, Universitat de Vic: FACSO México, pp. 161-188. Disponible en: < http://www.planetaweb2.net/> [Fecha de consulta: 5 de diciembre de 2013]. 
ELMUNDO.es. (2011), El creador del concepto 'Web 2.0' asegura que a pesar de su éxito 'está obsoleto' [en línea]. ELMUNDO.es, 23 de noviembre de 2011. Disponible en: <http://www.elmundo.es/elmundo/2011/11/22/ navegante/1321978250.html>. [Fecha de consulta: 7 de agosto de 2013].

García Markina, M. (2010), En contra de la Web 2.0 [en línea]. Disponible en: <http://www.slideshare.net/mikelg arciamarkina/contra-la-web-20 $>$ [Fecha de consulta: 23 de septiembre de 2013].

Margaix Arnal, D. (2007), "Conceptos de Web 2.0 y Biblioteca 2.0: origen, definiciones y retos para las bibliotecas actuales". El profesional de la información, vol. 16, núm. 2, pp. 95-106.

Monsoriu, F. M. (2010), Diccionario Web 2.O. Madrid: Creaciones Copyright.

O'Reilly, T. (2005), What is Eeb 2.0: Design Patterns and Business Models for the Next Generation of Sofware [en línea]. Disponible en: < http://oreilly.com/web2/archive/ what-is-web-20.html>. [Fecha de consulta: 15 de septiem bre de 2010].

Vélez Barreiro, M. (2006), La popularización del lenguaje español en la economía, la empresa y las finanzas [en línea]. Disponible en: <http://webs.ono.com/garoza/G6 -Velez.pdf $>$. [Fecha de consulta: 16 de septiembre de 2010]. 


\title{
Usuarios 2.0: definición
}

\author{
JuAn José Calva GonZález \\ Universidad Nacional Autónoma de México
}

ctualmente, la Web 2.0, así como todas las herramientas que
le son implícitas están en un desarrollo exponencial y cada
día se usan más en diferentes ámbitos y no sólo en el de las bibliotecas o el de los usuarios de la información. Es indudable que el usuario actual de la información está estrechamente ligado con el uso de las diversas posibilidades que tiene la Web 2.0, no sólo para obtener una amplia comunicación bidireccional y masiva, sino también para buscar la información que necesita para cubrir sus necesidades informativas. Además, el uso de las bibliotecas, o cualquier otra unidad de información para satisfacer las crecientes necesidades informativas de sus usuarios, es cada vez mayor e implica una infraestructura muy compleja; esto es así debido a las enormes ventajas que posee esta nueva plataforma. Es preciso entonces, mencionar con mayor especificidad qué es lo que se entiende por Web 2.0.

Podríamos comenzar por comprender que la Web 2.0 "[...] es un cambio de status de Internet, al igual que el cambio de estatus de un fichero de sólo leer hacia leer y escribir". ${ }^{1}$ Esta virtud que posee es precisamente aquello donde se engloba su definición, ya que las páginas web estáticas sólo le daban información en un sentido al usuario que acudía a ellas; ahí soló el autor de dicha página podía actualizar o incrementar la información, mas no así los que la con-

1 Web 2.0: nuevas formas de aprender y de participar. Coordinadores: Mariona Grané y Cilia Willem, Barcelona, Laertes educación, 2009, p. 22. 
sultaban. Así, una primera definición podría ser: "La web 2.0 es una nueva generación de servicios y aplicaciones Web en línea que facilitan la publicación, el compartir y la difusión de contenidos digitales, que fomentan la colaboración y la interacción en línea y que ofrecen unos instrumentos que facilitan la búsqueda y la organización de la información en línea". ${ }^{2}$ Esta definición de Grané muestra que la concibe como una generación de servicios y aplicaciones, con las cuales no sólo es posible la interacción sino también la búsqueda de información, esto es muy relevante, como se verá en los capítulos siguientes de este libro, cuando se traten los estudios de usuarios llevados a cabo en diferentes ámbitos. Y también, veremos su utilización en el ámbito de las bibliotecas, sobre todo las universitarias.

Por otro lado, O’Reilly nos da una definición en la cual dice que la Web 2.0 es una plataforma en donde todos los usuarios están conectados, que ofrece una serie de ventajas y en la que tienen cabida múltiples programas (software) que pueden ser continuamente utilizados como servicios por los usuarios para que un mayor número de personas puedan aprovechar; así como usar y rehusar una gran variedad de recursos, que incluyen usos individuales, y en donde se contemplen también datos propios y de otros usuarios en una interacción continua que crea una red y una arquitectura de participación en esta misma. ${ }^{3}$ De lo anterior se puede partir para dar paso a su utilización en los servicios

$2 \quad$ Ibid., pp. 31-32.

3 Veáse: Elizabeth Black, "Web 2.0 and library 2.0: What Librarians Need to Know". En Library 2.0 and Beyond: Innovative Technologies and Tomorrow's User. Edited by Nancy Courtney, Foreword by Steven J. Bell. Westport, Connect.: Libraries Unlimited, 2007, p. 2. En donde la autora menciona: "Web 2.0 is the network as platform, spanning all connected devices; Web 2.0 applications are those that make the most of the intrinsic advantages of that platform: delivering software as a continually updated service that gets better the more people use it, consuming and remixing data from multiple sources, including individual users, while providing their own data and services in a form that allows remixing by others, creating network effects through an "architecture of participation", and going beyond the page metaphor of Web 1.0 to deliver rich user experience". 
que ofrece una biblioteca; así, como lo menciona Bradley, ${ }^{4}$ la Web 2.0 ofrece nuevos e interesantes recursos para que los bibliotecarios continúen haciendo lo que hasta ahora venían haciendo desde tiempos pasados, brinda mayor orden y hace que la información sea más accesible, sólo que ahora hay que observar cómo pueden seguir haciéndolo con esta nueva tecnología.

La idea de tener sólo hipervínculos en las páginas web y sustituirla por la idea de interactuar con alguien vía un sitio web usando una plataforma con arquitectura de participación, y la conformación de todo un entrelazado o red de relaciones con todos los participantes de manera bidireccional es algo completamente nuevo a lo que se tenía anteriormente con la web primaria. ${ }^{5}$ La idea de una interacción a través de esta plataforma y la de incluir toda una gama de servicios y herramientas para que todo funcione, forma parte de esta concepción de la Web 2.0, de la cual las personas o usuarios de la información pueden beneficiarse, así como también otras instituciones, como las bibliotecas.

La aparición de la Web 2.0 en Internet continúa con el desarrollo de esta tecnología y quizá su apropiación por las grandes masas es su rasgo principal; esta forma de adueñarse de las herramientas que proporciona la Web 2.0 es de gran importancia para los ciudadanos comunes porque pueden interactuar no sólo con los softwares sino también con los sujetos que están del otro lado de la conexión a través de esta plataforma y en tiempo real; para las bibliotecas, y otras organizaciones, esto significa una mayor interacción con sus usuarios/clientes y una mejor forma de intercambiar información o de buscar información en toda la red.

Estas formas de explicar la Web 2.0 nos permiten hablar del Usuario 2.0 y de la Biblioteca 2.0. En este contexto, entonces, el usuario tampoco es el mismo que habíamos visto en la versión anterior, ya que remontarnos al diseño y uso de las páginas web cuando éstas eran rígidas y no flexibles y sólo podían utilizar los hipervínculos

4 Bradley, P. How to Use Web 2.0 in Your Library. London: Facet Publishing, 2007.

5 Cfr. D. M. Arnal, Informe APEI sobre web social, pp. 7-9. 
para conectar de una página a otra donde posiblemente había imágenes y sonido, no nos resolvería nada. Pero con la aparición de esta plataforma y su arquitectura de participación, la situación cambió rotundamente para el usuario de esta tecnología. Esto es así debido a que las herramientas ligadas con la Web 2.0 permiten que el usuario modifique, aporte, critique o introduzca información a los sitios que tienen esta plataforma. Esto le gustó indudablemente a toda la comunidad de usuarios de Internet, y un ejemplo son los blogs, que "[...] representan todo el movimiento generado en torno a la Web 2.0, su sencillez de uso y de publicación, la facilidad con que se puede crear y mantener, la visibilidad que tiene en los resultados de los motores de búsqueda y su flexibilidad para construir una herramienta de conversación adaptada a las necesidades concretas son sin duda clave de su éxito" ${ }^{6}$ La aparición de los blogs como una de las partes de la web conforma esa figura llamada Usuario 2.0 ya que éste se adapta con mayor rapidez y con mayor aceptación al uso de esta plataforma y sus herramientas, en tanto le permiten tener mucho mejor comunicación vía la herramienta, con otros sujetos conectados e intercambiar comentarios, datos, imágenes, sonido, etc; es decir, existe una bidireccionalidad, y esto es precisamente lo que va a caracterizar al Usuario 2.0, ese "va y viene" que obtiene gracias al medio. Entonces, el Usuario 2.0 conlleva en su definición esa bidireccionalidad que entabla conexiones y comunicación con otros usuarios 2.0 y le permite mantener una relación reciproca de intercambio; las redes sociales como Facebook serían un ejemplo más profundo, además de los mencionados blogs.

El Usuario 2.0 es aquel que está inmerso en las herramientas de la misma Web 2.0 y que, está ávido de aportar, de ser escuchado, de criticar o de felicitar, y es quien puede buscar información a través de los blogs, las wikis, las redes sociales y utilizar al máximo toda la hiperconectividad, no sólo con las personas, sino con toda la serie de recursos y fuentes de información que se encuentra en Internet. Es también quien espera que la biblioteca se

$6 \quad$ Ibid., p. 11. 
comunique con él a través de alguna de estas posibilidades, como por ejemplo Facebook o un blog. E igualmente espera que a través de estos medios, la biblioteca le haga llegar la información que necesita o le permita buscar información en las colecciones de la misma, sobre todo recordando que mucha de esa información ya está en formato digital.

Hablar de un Usuario 2.0 de la información implica, entonces, la existencia de una Biblioteca 2.0 que puede ser considerada como un modelo de servicios bibliotecarios y de la información que cuenta con un desarrollo y cambio constantes y donde la participación del usuario está presente en la creación de servicios físicos y virtuales que él quiere que la biblioteca le ofrezca. ${ }^{7}$ Pero, independientemente de que exista la biblioteca 2.0, la existencia del Usuario 2.0 de la información (audiovisual y textual) se da por el hecho de que éste usa todas o casi todas las herramientas de la Web 2.0, y que tiene la destreza para buscar a través de éstas la información que cubra sus necesidades informativas. De esta manera, si existen Bibliotecas 2.0 que usen las mismas herramientas, este nexo, esta conexión será completa y en un ambiente de este tipo, la búsqueda y recuperación de información siempre estará a su alcance y por lo tanto podrá acceder a ella.

7 Véase lo que dice Black sobre la apreciación de Casy y Savastinuk. Op. cit., Black, E. ...p. 10. "A model for library service that encourages constant and purposeful change, inviting user participation in the creation of both the physical and the virtual services they want, supported by consistently evaluation services. It also attempts to reach new users and better serve current ones through improved customer-driven offerings. Each component by itself a step toward better servicing our users; however, it is through the combined implementation of all of these that we can reach Library 2.0". 


\section{BIBLIOGRAFÍA}

Web 2.0: nuevas formas de aprender $y$ de participar (2009). Coordinadores: Mariona Grané y Cilia Willem. Barcelona: Laertes educación, p. 22.

Black, E. (2007), "Web 2.0 and library 2.0: What Librarians Need to Know". En Library 2.0 and Beyond: Innovative Technologies and Tomorrow'S User. Edited by Nancy Courtney, Foreword by Steven J. Bell. Westport, Connect.: Libraries Unlimited.

Bradley, P. (2007), How to use Web 2.0 in Your Library. London: Facet Publishing.

Arnal, D. M. (2008), Informe APEI sobre web social. Gijón: Asociación Profesional de Especialistas en Información. 


\title{
Usuarios 2.0: características y tipología
}

\author{
ISABEL VILLASEÑOR RODRÍGUEZ \\ Universidad Complutense de Madrid
}

$\mathbf{P}$

odríamos afirmar que el Usuario 2.0 se caracteriza por formar parte de la "Cultura 2.0", un fenómeno tecnosocial que se ha desarrollado en los últimos años y que, en la actualidad, se encuentra en su máximo esplendor. Es en este contexto en el que, como dice Fumero, "[...] interactúan lo social (cómo y dónde nos comunicamos y relacionamos) y lo tecnológico (nuevas herramientas, sistemas, plataformas, aplicaciones y servicios), provocando cambios de lo uno sobre lo otro". ${ }^{1}$ Esta cultura, aprovechando la democratización o popularización de las nuevas tecnologías, se fundamenta en una nueva concepción social del ser humano que tiene que ver con el deseo de compartir, estar informado y comunicarse. En este sentido, y aunque no es éste el principal interés de nuestro estudio, necesitamos una idea de la cual partir para afrontar el concepto de "Cultura 2.0". Por eso, de entre todas las posibles, nos basaremos en la definición de "cultura" o "civilización" que ofrece Tylor cuando dice que: "[...] en sentido etnográfico amplio, es aquel todo completo que incluye el conocimiento, las creencias, el arte, la moral, el derecho, las costumbres y cualquier hábito y capacidades

1 A. Fumero y G. Roca, con la colaboración especial de Fernando Sáez Vacas, p. 11. 
adquiridas por el hombre en cuanto miembro de la sociedad". ${ }^{2}$ Por su parte, Domingo Barbosa, Alfonso Vázquez, Jesús Seco y Juan Manuel Jiménez, distinguen entre Cultura 0.0 y Cultura 2.0.", afirmando que la primera parte de la cultura general como contraposición a la ideada desde el espectro de la Red, del ciberespacio, titulada Cultura 2.0. Ambas distintas y distantes que pugnan por la hegemonía de lo real. La primera, supone lo consciente y lo vivido; la segunda, lo virtual, imaginación de la primera. Estos autores señalan la igualdad de ambas, considerando la 2.0 como prolongación necesaria para comprendernos y seguir existiendo en la realidad. Es mucho más que lo entendido como "realidad virtual": empaqueta actos, creencias, valores que abarcan toda la experiencia social, organizando la sociedad desde esa posibilidad de intercambio y comunicación.

El profesor Figueroa Alcántara, por su parte, sintetiza perfectamente el sentido de esta cultura cuando dice que se trata de la cultura de obsequiar, compartir, colaborar, reconocerse y solidarizarse en la sociedad red. Es una cultura símbolo de un nuevo movimiento social que cuenta, entre sus atributos, con la libre circulación de información, la colaboración, el intercambio de conocimientos, la generosidad para ayudar a otros, la reciprocidad, la solidaridad, la crítica abierta y el reconocimiento social de los mejores dentro de la comunidad, sustentándose en unos principios que caracterizan al Usuario 2.0 y que son, entre otros, que toda la información sea de libre acceso y circulación y que todo usuario desee colaborar, transmitir y compartir.

El Usuario 2.0 desarrolla nuevos usos sociales y nuevas formas de comunicación, fomentando la libre circulación de información, la colaboración y el intercambio de conocimientos a través de tecnologías que ya no están sólo en manos de expertos. Se enriquece con los contenidos generados por otros usuarios y obsequian los creados por él. Su presencia en Internet es cada vez más frecuente y numerosa; su tipología, muy variada. Este usuario utiliza con mayor o menor habilidad todos los recursos técnicos nacidos en un entor-

2 E. B. Tylor, Primitive Culture: Researches into the Development of Mythology, Philosophy, Religion, Art and Custome, p. 10. 
no cambiante, innovando e involucrándose en su desarrollo. Algunos de estos recursos son los foros de discusión, de mensajes o de opinión, los blogs, los portales webs, el correo electrónico, los grupos de noticias, los chats, los mundos virtuales, las wikis, las redes sociales, etc. Son herramientas y servicios diseñados y difundidos para animar a la participación, al intercambio libre y gratuito de información; herramientas y servicios complejos aunque intuitivos y fáciles de usar. De todos ellos, cabe destacar el de las redes sociales por ser el más extendido. En este sentido, y como dicen Nicholas A. Christakis y James H. Fowler:

"[...] las nuevas tecnologías [...] se limitan a hacer posible nuestra ancestral tendencia a conectar con otros humanos [...] Por muy abstractas, grandes, complejas y supermodernas que sean las redes sociales formadas en el ciberespacio, siguen reflejando tendencias humanas universales y fundamentales que aparecieron en nuestra prehistoria, cuando nos contábamos historias alrededor de una hoguera en la sabana africana", 3 porque 'los seres humanos somos animales sociales que vivimos en grupos y próximos unos de otros...Nuestras relaciones con otros seres humanos son cruciales, la sociabilidad humana y las redes sociales tienen antiguas raíces genéticas. ${ }^{4}$

Las redes sociales virtuales vienen a desarrollar las naturales y reales, las que siempre han existido basándose en conexiones establecidas entre las personas que las componen. El desarrollo de la tecnología ha hecho que cambie la forma en que nos conectamos gracias, entre otras cosas, a la no limitación geográfica o por timidez o discriminación y al inmenso poder para multiplicar los efectos de cualquier iniciativa. En este sentido, Ugarte ${ }^{5}$ habla de una red distribuida, basada en una multiplicidad de agentes

3 N. A. Christakis y J. H. Fowler, Conectados: El sorprendente poder de las redes sociales y cómo nos afectan, pp. 266-267.

$4 \quad$ Ibid., p. 224.

5 D. de Ugarte, El poder de las redes. Manual ilustrado para personas, colectivos y empresas abocadas al ciberactivismo. 
que actúan autónomamente, coordinándose espontáneamente en la red, al margen de las clásicas formas y jerarquías y con manifestaciones tales como el ciberactivismo o la blogsfera.

El Usuario 2.0 entiende las relaciones sociales de forma diferente al estar imbuido en un contexto marcadamente tecnológico que le permite crear, aportar, difundir, compartir y colaborar. No importa tanto lo que sabe o deja de saber sino cómo lo comunica en su afán por contribuir a la generación de conocimiento colectivo. Se trata de un usuario que actúa, siendo él quien tiene la capacidad de elegir entre la diversidad de posibilidades que existen, y que aporta, crea, informa y difunde. Pero también se constituye en una parte de un todo que lo afecta y con el cual se vincula, perdiendo parte de su individualidad, hasta el punto de dejarse influir (consciente o inconscientemente) por las opiniones, informaciones o acciones que aporten los demás, en un contagio que posibilitan las redes sociales al jugar un importante papel en la propagación de emociones. De cualquier forma, el Usuario 2.0 forma parte de una o varias comunidades porque es un ser sociable y se reconoce como individuo en la sociedad, deseando interactuar para satisfacer sus necesidades o llevar a cabo roles específicos, compartiendo un proyecto determinado que constituye la razón de ser de su grupo, utilizando una tecnología que le facilita su propósito (personal o profesional) y actuando en un ámbito que siente como propio y al cual pertenece.

La importancia de la existencia de este Usuario 2.0 hace que nos planteemos la necesidad de conocerlo mejor y de una manera sistemática. Para ello, pueden utilizarse distintas metodologías. Domingo Barbosa, Alfonso Vázquez, Jesús Seco y Juan Manuel Jiménez ${ }^{6}$ proponen la aplicación de la metodología clásica” de ciencias sociales como la antropología, la etnografía y la sociología, al ciberespacio, justificando por qué la antropología ha de ocuparse del estudio de éste cuestionando si las técnicas tradicionales de la Etnografía son

6 CULTURA 2.0. Técnicas de investigación en entornos digitales. Domingo Barbosa, Alfonso Vázquez, Jesús Seco, Juan Manuel Jiménez. Barcelona: UOC, 2010. 
aplicables a este nuevo entorno inmaterial. Para ello, hablan de la ciberantropología, subdisciplina de la antropología que se ocupa del estudio etnográfico de las relaciones entre los hombres y las máquinas a finales del siglo $\mathrm{XX}$, en el que las nuevas tecnologías sirven como agentes de producción social y cultural. Estos estudios crecen y se reorientan a investigar las comunidades electrónicas desde la perspectiva de los contextos donde las tecnologías del ordenador se desarrollan, hasta las interacciones entre los diseñadores, los usuarios y las comunidades que resultan de esa interacción, a veces imaginadas e inventadas, pero capaces de crear nuevas identidades, como los ciborgs o vecinos electrónicos, así como a vivir en regiones y comunidades que resultan de esa interacción. Estudios que crecen y abordan cada vez más facetas y dimensiones de los entornos digitales, y que cubren a los diversos grupos de población implicados y las innovaciones, tanto tecnológicas como sociales, que surgen a una velocidad vertiginosa.

La consideración de que la Cultura 2.0 es prolongación necesaria de la Cultura 0.0 para comprendernos y seguir existiendo en la realidad, resulta de gran novedad ya que asegura la igualdad de ambas. Por otra parte, los autores defienden la etnografía como viejo método de trabajo e investigación antropológica perfectamente válida para aproximarnos a las nuevas tecnologías, una vez que se haya adaptado a las peculiaridades concretas con las que lo ciborg nos desafía. La Antropología nos permite descubrir el ordenamiento intrínseco de la sociedad ese descubrimiento nos permite comprender, y esa comprensión nos llevará a mejorar la calidad de vida de los miembros de este nuevo sistema. Entre las técnicas a utilizar proponen, entre otras, las entrevistas en profundidad, los grupos de discusión, las encuestas en la red, el análisis de contenido de mensajes escritos u orales, las "historias de vida", la observación participante, las técnicas audiovisuales, etc. 


\section{Tipología}

Obviamente, hay tantos perfiles de Usuarios 2.0 como individuos diferentes navegando por Internet. Por lo tanto, es casi imposible definir un perfil determinado que corresponda a una comunidad de usuarios que tenga características comunes. Lo que importa ahí realmente es tener en cuenta no tanto al individuo sino a la comunidad de la que forma parte. En este sentido, Gallego Vázquez considera que lo esencial son las comunidades, entendidas como un "[...] grupo de personas que comparte un mismo fin y voluntariamente se asocian para conseguirlo". ${ }^{7}$ Para este autor hay una serie de elementos que definen una comunidad: sus objetivos, que son comunes (los que aglutinan a la comunidad) y personales (específicos de cada integrante y no necesariamente iguales al común); la identidad, ${ }^{8}$ el reconocimiento, para incentivar a los miembros a incrementar su colaboración; las normas como barreras de entrada, de promoción, de comportamiento, de recompensa y de salida; el medio, físico o virtual, donde interactúan los integrantes de la comunidad y que permite su desarrollo y la comunicación entre sus miembros; la jerarquía, para motivar y reconocer el esfuerzo de los usuarios; el compromiso, y el líder, el elemento más importante en las fases iniciales de toda comunidad. Y distingue tres tipos de comunidades:

- Activas: "[...] grupo de personas que tienen un fin común y cuentan con las herramientas sociales necesarias para llevar ese fin a cabo. Normalmente [...] llevan ya tiempo en marcha y cuentan con sus líderes, sus medios y sus objetivos propios"?

7 J. A. Gallego Vázquez, Todo lo que hay que saber de comunidades virtuales $y$ redes sociales, p. 28.

8 "El miembro de la comunidad debe ser consciente de su pertenencia, y sentirse parte de ella, y elemento necesario en su desarrollo". Ibid., p. 69.

$9 \quad$ Ibid., p. 79. 
- Latentes: “[...] las creadas a partir de [...] la detección de una necesidad o inquietud por parte de un grupo de personas que no tiene contacto entre sí, y la creación de una plataforma que permite a todas esas personas ponerse en contacto y construir la comunidad". ${ }^{10}$

- Instantáneas: "sin continuidad espacio-temporal".11

Hasta el momento, son escasos los trabajos de carácter teórico que afronten una tipología de Usuarios 2.0. En la bibliografía consultada hemos podido ver algunas clasificaciones y caracterizaciones de usuarios en la red fundadas esencialmente en resultados obtenidos a través de trabajos de campo. Así, el antropólogo Vázquez Atochero $^{12}$ nos dice que existen diferentes tipos de comunidades virtuales con características particulares y se basa en los resultados obtenidos de una investigación llevada a cabo por observación participante en la red mediante visitas y el registro de múltiples comunidades, observando las pautas de comportamiento de sus componentes, las posibilidades de cada comunidad y la manera en que los nuevos miembros se posicionaban en la red. Algunas de estas comunidades son los BBS (bulletin board system-sistema de tablero de anuncios), los foros de discusión, de mensajes o de opinión, la blogosfera, entendida como conjunto de webblogs repartidos por el ciberespacio, los portales web, los grupos de correo electrónico (las listas de correo o listas de distribución), los grupos de noticias, los chats, etc. De todos ellos, el autor da cuenta, a su vez, de los distintos tipos de usuarios que forman parte de algún foro de discusión, a los que llama genéricamente "foreros" o "foristas". Contamos con foros generales y temáticos, abiertos o restringidos y usuarios registrados o invitados, activos o latentes; entre ellos están los lurkers (que leen pero no escriben), los spamers (que introducen publicidad en los foros), los troles (que insultan o molestan a otros usuarios), los leechers (que sólo obtienen beneficios, sin

10 Ibid., p. 84.

11 Ibid., p. 94.

12 A. Vázquez Achero, Ciberantropología. Cultura 2.0. 
aportar nada a cambio), los fakes (que se hacen pasar por otros miembros), los títeres (inscritos en el foro dos o más veces haciéndose pasar por diferentes miembros), los chaters (que utilizan un lenguaje casi jeroglífico, herencia de los mensajes sms), los arqueólogos (que se afanan en tener en primera página temas antiguos), los novatos (que participan sin tener en cuenta las normas de la comunidad), el administrador (normalmente creador del foro, puede eliminar o corregir a los usuarios y cuenta con un status especial) y los usuarios moderadores (que tienen la potestad para controlar cierto tipo de intervenciones e incluso eliminar mensajes que se consideren no adecuados).

Dolors Reig ${ }^{13}$ da a conocer otra tipología basándose en aspectos relacionados con las actitudes y conductas de los usuarios de redes sociales que, en su día, estableció OFCOM. ${ }^{14}$ Podemos encontrar:

- Alpha socializers: personas que usan los sitios sociales en intensos y cortos periodos de tiempo para flirtear, conocer gente nueva o entretenerse.

- Buscadores de atención: personas que buscan la atención y los comentarios de los demás, "posteando" (subiendo a la red) fotos y personalizando sus perfiles.

- Seguidores: personas que se unen a sitios sociales para estar al día de las actividades de sus contactos en la vida real.

- Fieles: personas que usan las redes sociales para recuperar amistades del pasado.

- Funcionales: personas que tienden a usar los sitios de redes sociales con un único objetivo puntual.

- No usuarios: pueden clasificarse en distintos grupos, con base en las razones que se aducen para no utilizar redes sociales, tales como la preocupación por la seguridad, la poca

13 D. Reig, Actitudes, comportamiento, usos, clasificación de los usuarios de las redes sociales.

14 Organización reguladora independiente para las industrias de la comunicación en Reino Unido. 
experiencia técnica o motivos intelectuales al suponer las redes sociales como una pérdida de tiempo.

Domingo Barbosa, Alfonso Vázquez, Jesús Seco, Juan Manuel Jiménez, al considerar la red como nuestro territorio, nuestra aldea global, afirman que los usuarios son la tribu, y una tribu con ciertas características irrepetibles, ya que un mismo usuario suele tener una identidad en cada escenario: en su vida física y en su vida virtual. Cada usuario tiene su rol y su función en este espacio virtual. Para poder comprender de forma amplia y globalizada esta tribu, se tendrán en cuenta no sólo a quienes están integrados en las nuevas tecnologías, sino a aquellos que por una u otra razón se han ido quedando al margen. Todos estamos dentro (aborigen digital), la diferencia es que unos controlan este medio y otros no. Entre los excluidos y los integrados, se abre la brecha digital (desigualdades económicas, sociales y personales). Para estos autores existe, pues, una gran diversidad de pobladores en esta aldea, entre los que destacan:

- Nativos digitales: los nacidos en un entorno ya tecnificado.

- Inmigrantes digitales: han conocido la época previa y se introducen en la sociedad red a medida que las tecnologías han llegado a sus vidas. En este sentido, Fumero y Roca dicen que se han incorporado a Internet "[...] entre otros factores por las sucesivas olas de alfabetización impulsadas entre otros por las diferentes administraciones públicas para minimizar el riesgo de brecha digital. De hecho, son esos esfuerzos los que han ayudado a descubrir que la brecha se manifiesta múltiple y diversa". ${ }^{15}$

- Fóbicos sociales: encerrados en sus cuatro paredes tienen como única ventana al mundo la red de redes, con la que tienen la posibilidad de explorar, construir, reconstruir y jugar con distintas identidades, de crear identidad, escon-

15 Op. cit., pp. 10-11. 
derse detrás de un rol; no hay un perfil: cualquier persona, independientemente de su edad, sexo, nivel económico o sociocultural puede padecer este trastorno.

Ramón Rautenstrauch, ${ }^{16}$ por su parte, dice que, en las redes sociales podemos clasificar a los usuarios en los siguientes perfiles, según su participación en los medios sociales:

- Creador (creator): publica una web, mantiene un blog, publica videos y música o artículos que ha creado.

- Conversador (conversationalists): actualiza sus estados en redes sociales y publica en Twitter.

- Crítico (critics): comenta en otros blogs/foros, publica análisis de productos/servicios y contribuye a escribir/editar artículos en wikis.

- Coleccionista (collectors): usa fuentes RSS, vota por páginas webs y etiqueta páginas/fotos.

- Participativo (joiners): tiene perfiles en redes sociales y los mantiene.

- Espectador (spectators): lee blogs, escucha podcasts, ve videos de otros, lee foros, análisis de productos/servicios y tweets.

- Inactivo (inactives): No hace nada de todo esto.

Por último, existen distintas variables a tener en cuenta: sexo (el acceso a la red presenta una oportunidad de expansión sin discriminación; en la Sociedad 2.0 el porcentaje de mujeres es más elevado que el de hombres, al menos en el mundo occidental); clase social (el acceso a Internet está condicionado por infraestructuras marcadas por factores económicos; Internet no es una necesidad vital y a veces es un lujo; resulta una utopía la idea de "Internet para todos" y es evidente la existencia de la brecha digital); edad (la red está tomada mayoritariamente por jóvenes y adolescentes

16 R. Rautenstrauch, Tipos de usuarios en Redes Sociales, s.p. 
con un interés lúdico y comunicativo, principalmente); ubicación espacial (el acceso a la red es más sencillo en el mundo occidental y en las zonas urbanas; donde más población se condense y más ingresos pueda generar, allí habrá mayor conexión; en países con economías menos favorecidas, el acceso es de peor calidad y menos extendido); profesión (si el trabajo es un componente básico del sistema social, ineludiblemente no podrá escapar a los cambios que afectan a ésta; hay quien necesita la red para su trabajomedio y quien tiene la red en sí como trabajo-fin), uso de la tecnología (según se dé su relación con ella, tenemos usuarios iniciales, usuarios medios y usuarios expertos, y, según interactúen con ella, usuarios pasivos, participativos y cooperativos).

\section{BIBLIOGRAFÍA}

CULTURA 2.0 (2010), Técnicas de investigación en entornos digitales. Domingo Barbosa, Alfonso Vázquez, Jesús Seco, Juan Manuel Jiménez. Barcelona: UOC.

Christakis, N. A., y Fowler James H. (2010), Conectados: El sorprendente poder de las redes sociales y cómo nos afectan. Barcelona: Taurus.

Fumero, A. y Roca, G. (2007), Con la colaboración especial de Fernando Sáez Vacas. Web 2.0. Madrid: Fundación Orange España.

Gallego Vázquez, J. A. (2011), Todo lo que hay que saber de comunidades virtuales y redes sociales, Madrid: Wolters Klumer España.

Rautenstrauch, R. (2013), Tipos de usuarios en Redes Sociales. Disponible en: <http://www.netconsultingmarke ting.es/tipos-de-usuarios-en-redes-sociales/>. [Fecha de consulta: noviembre 2013]. 
Reig, D. (2009), Actitudes, comportamiento, usos, clasificación de los usuarios de las redes sociales. Disponible en: <http://www.dreig.eu/caparazon/2009/02/09/ac titudes-comportamiento-usos-clasificacion-de-los-usua rios-de-las-redes-sociales/ $>$. [Fecha de consulta: noviembre 2013].

Tylor, E. B. (1873), Primitive Culture: Researches into the Development of Mythology, Philosophy, Religion, Art and Custome, London: John Murray.

Ugarte, D. de (2007), El poder de las redes. Manual ilustrado para personas, colectivos y empresas abocadas al ciberactivismo. Barcelona: El Cobre Ediciones, 2007. Colección Planta, 29.

Vázquez Achero, A. (2008), Ciberantropología. Cultura 2.0. Barcelona: UOC. 


\title{
Relación de usuarios 2.0 con diferentes redes sociales para la recuperación e intercambio de información audiovisual y textual
}

\author{
Juan José Calva GonZález \\ Universidad Nacional Autónoma de México
}

\section{INTRODUCCIÓN}

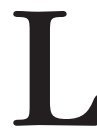

os usuarios tradicionales de las bibliotecas, y otras unidades de información similares, acuden a ellas para obtener la in2.0?, pues éstos pueden acceder a la información desde una conexión con Internet, donde quiera que ésta esté, para lo cual pueden utilizar las herramientas de la Web 2.0 o posiblemente, ya tienen acceso a una Biblioteca 2.0 pues ahí está la información que necesitan.

A partir de la elaboración del proyecto Usuarios 2.0 de la información audiovisual y textual, se llevó a cabo una serie de investigaciones más acotadas en diferentes comunidades sociales: alumnos de secundaria y de licenciatura, y su relación con la biblioteca universitaria, publica o escolar, con la finalidad de ver la relación del Usuario 2.0 con las diferentes redes sociales. Además de identificar el tipo de redes sociales o herramientas de la Web 2.0 que utilizan para buscar la información que necesitan, o encontrar como usan estas herramientas, no solo para la comunicación sino también para el intercambio de información.

Las nuevas generaciones de hombres y mujeres que están rodeados de esta tecnología, y la cual ya es más accesible y con un costo no muy elevado, ha permitido que la Web 2.0 y por lo tanto el Usuario 2.0 se desarrolle rápidamente; así es como se observa que 
los jóvenes de preparatoria, secundaria e inclusive los de primaria cuentan con un teléfono celular que puede conectarse a Internet casi desde cualquier lugar (sobre todo si el WiFi es público) o, si tienen una tableta con muchas funciones para la utilización de redes sociales y otras herramientas de la Web 2.0. Estos dispositivos móviles abrieron una amplia gama de posibilidades de comunicación, es decir, los jóvenes están en constante comunicación con otros, y no solo utilizan este medio para decir cosas triviales, sino que también lo usan para intercambiar información académica, información escolar, e información de tipo general que es la que fluye por este medio siguiendo los caminos de una red.

Las herramientas de la Web 2.0 también pueden ser utilizadas como buscadores de información y por lo tanto estar interconectadas con profesores, escuelas, bibliotecas y otro tipo de académicos e instituciones gubernamentales y de investigación. Ahora, es posible que esta tecnología pueda estar conectada en tiempo real y por lo tanto que las búsquedas, el intercambio y acceso a la información sean en el momento. Por lo tanto, diferentes tipos de comunidades sociales tienen acceso a la información que fluye en la web, solo es cuestión de buscar una conexión para poder tenerla.

Las diferentes comunidades de usuarios de la información que usan la Web 2.0 desde cualquier dispositivo fijo o móvil, entran en la interacción y flujos de información que hay en la red. Asimismo, al usar las redes sociales, por ejemplo, tienen la posibilidad de buscar la información que necesitan y obtenerla por este mismo medio. Podría pensarse que esto solo es posible en los niveles académicos altos y no en los niveles educativos básicos como podría ser, nivel secundaria, preparatoria o de licenciatura. Pero a través de una investigación que forma parte de este proyecto se puede ver cómo las redes sociales y otras herramientas de la Web 2.0 son utilizadas para obtener información y permitir los flujos de la misma. 


\section{FLUJO DE LA INFORMACIÓN \\ EN DIVERSOS NIVELES EDUCATIVOS}

A través de varias investigaciones llevadas a cabo con estudiantes de secundaria se puede investigar para qué usan el Internet como se muestra en la siguiente figura, en donde el $19 \%$ de los alumnos encuestados la usa para buscar información escolar. Asimismo, en esta investigación el 34\% de los encuestados utiliza Google para la búsqueda de información. ${ }^{1}$ Entonces, el Internet, sus buscadores y otro tipo de herramientas no sólo son utilizadas por los jóvenes para comunicarse con otros, sino que también las usan para buscar la información que necesitan, mucha de esta académica.

Figura 1. Uso de Internet

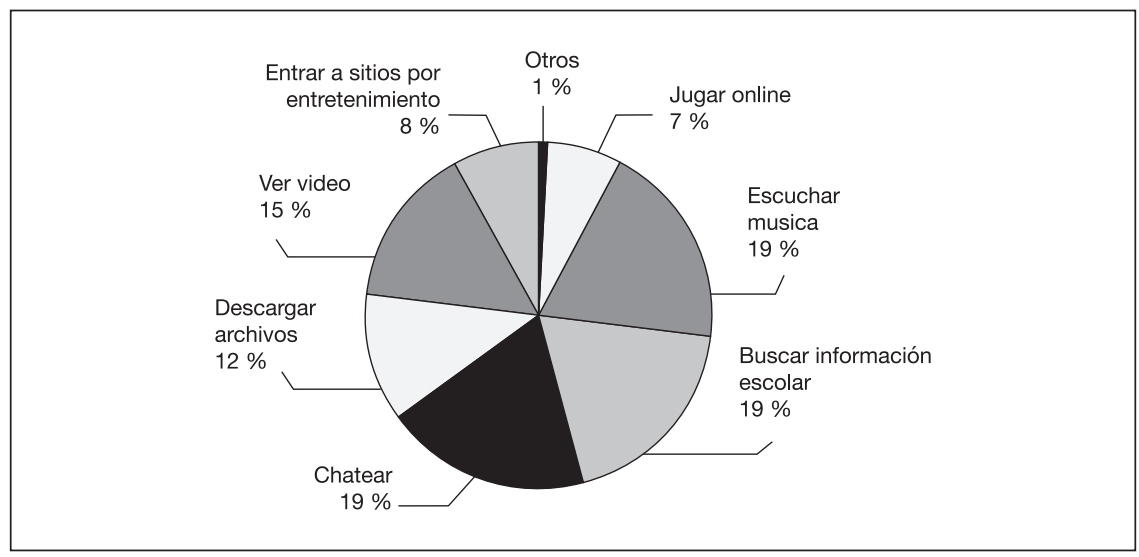

Fuente: Guzmán Prieto, Edgar. "El uso de las redes sociales para la búsqueda de información escolar de los alumnos de educación básica en el pueblo de San Gregorio Atlapulco y San Luis Tlaxialtemalco en Xochimilco", México: EGP, 2012, p. 43.

$1 \quad$ Cfr. Guzmán Prieto, E. El uso de las redes sociales para la búsqueda de información escolar de los alumnos de educación básica en el pueblo de San Gregorio Atlapulco y San Luis Tlaxialtemalco en Xochimilco, México: EGP, 2012, p. 44. 
Figura 2. Miembros de redes sociales

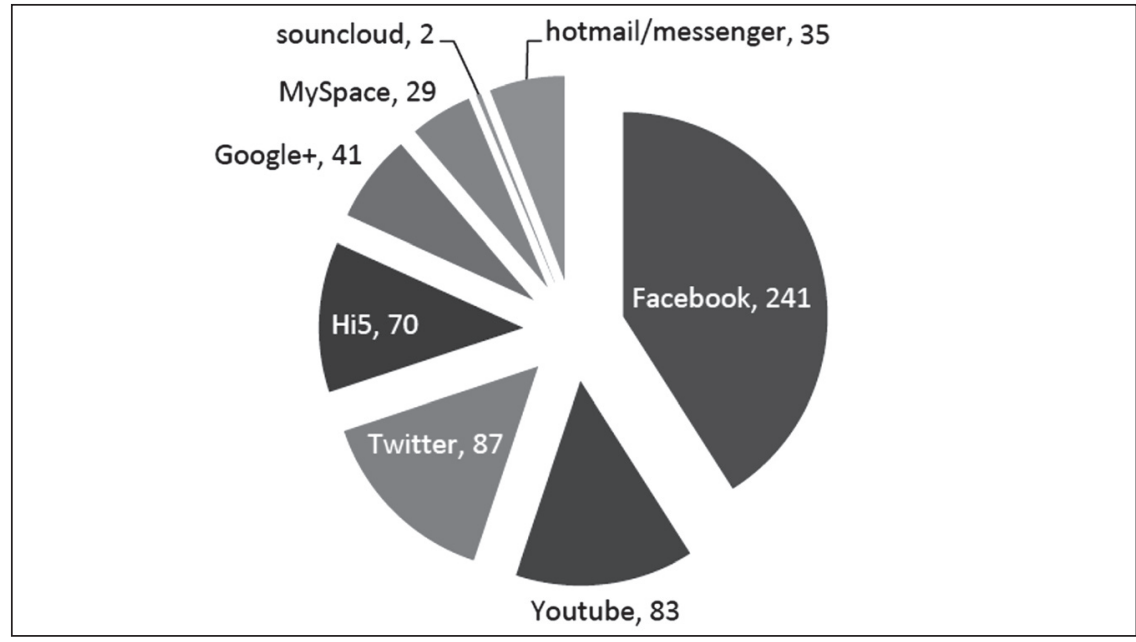

Fuente: Guzmán Prieto, Edgar. "El uso de las redes sociales para la búsqueda de información escolar de los alumnos de educación básica en el pueblo de San Gregorio Atlapulco y San Luis Tlaxialtemalco en Xochimilco", México: EGP, 2012, p. 49

En cuanto a las redes sociales a las que pertenecen o de las que son miembros, los alumnos de secundaria prefieren Facebook, seguido de Twitter y YouTube, es decir, que están utilizando las herramientas de la Web 2.0 para comunicarse con sus amigos o tener contacto con otras personas, pero hay que ahondar qué pasa con la búsqueda de información o en su caso, el intercambio de información de un sujeto a otro por medio de estas redes sociales, lo cual puede observarse en la Figura 3 (p. sig.).

Si se observa la Figura 3, el 12\% de los alumnos encuestados contestaron que usan las redes sociales para buscar información. Esto puede revelar el gran potencial que pueden tener las redes sociales para buscar y obtener información que necesitan los miembros de dicha red, y no solo ser utilizadas para mantener una comunicación con otras personas, aunque todavía se puede ver que las usan para chatear. 
Figura 3. Uso de redes sociales

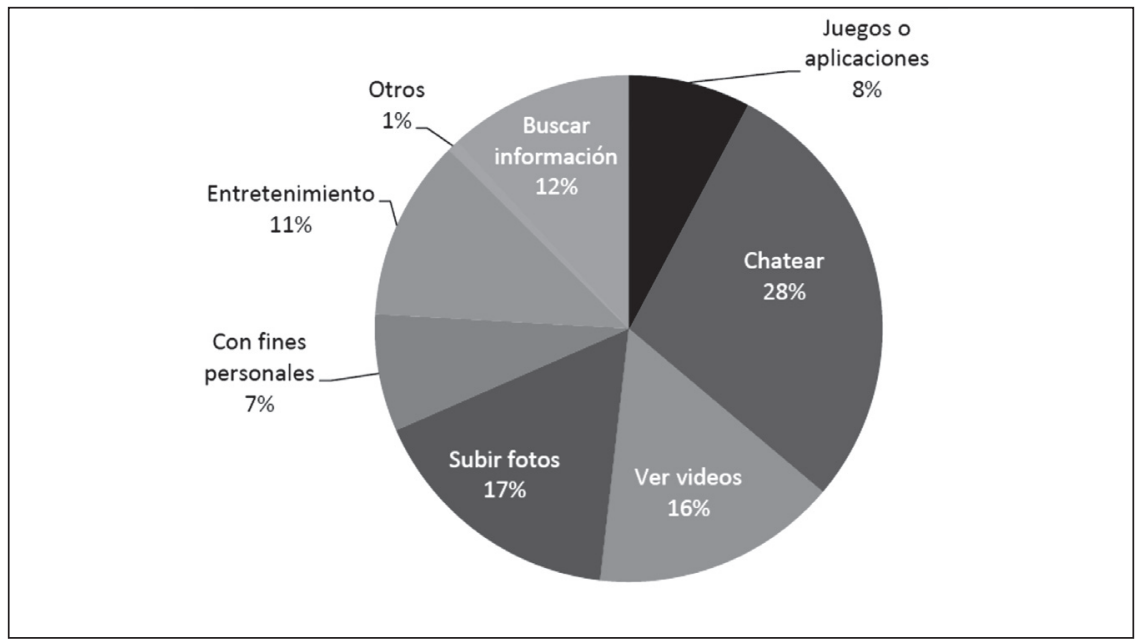

Fuente: Guzmán Prieto, Edgar. "El uso de las redes sociales para la búsqueda de información escolar de los alumnos de educación básica en el pueblo de San Gregorio Atlapulco y San Luis Tlaxialtemalco en Xochimilco", México: EGP, 2012, p. 52.

Tabla 1. Tipo de información que buscan y obtienen en las redes sociales

\begin{tabular}{|c|}
\hline Tipo de información \\
\hline Trabajos \\
\hline Tareas \\
\hline Investigaciones \\
\hline Trabajos en equipo (exposiciones) \\
\hline Pasar o pedir la tarea \\
\hline Suben la tarea \\
\hline Matemáticas, Historia y Cívica I \\
\hline Inglés \\
\hline Química \\
\hline
\end{tabular}

Fuente: Guzmán Prieto, Edgar. "El uso de las redes sociales para la búsqueda de información escolar de los alumnos de educación básica en el pueblo de San Gregorio Atlapulco y San Luis Tlaxialtemalco en Xochimilco", México: EGP, 2012, p. 53. 
Entonces, los alumnos usan el Internet, los buscadores y las redes sociales y, aunque los porcentajes aun sean bajos, los utilizan para buscar la información que necesitan, y si la tiene otro contacto, entonces la comparten en el muro donde será vista por un amplio número de alumnos o compañeros de grupo. Asimismo, un $63 \%^{2}$ de los encuestados ingresan a las redes sociales para buscar y obtener información a través del teléfono celular, lo cual indica que casi desde cualquier lugar pueden conectarse.

En otra investigación con otro grupo de estudiantes de secundaria en el Estado de México se puede notar que es la misma tendencia, es decir, que el uso que le dan a las redes sociales no es exclusivamente para mantener contacto con un amigo o compañero, sino que son usadas para buscar y obtener información.

En la Tabla 2 puede observarse que las herramientas de la Web 2.0 sí están siendo explotadas respecto a la búsqueda y obtención de la información para su trabajo escolar en más de un $67 \% .^{3}$

Tabla 2

\begin{tabular}{|l|c|c|c|}
\hline \multicolumn{1}{|c|}{ Según grado } & Grado “1”\% & Grado "2"\% & Grado “3”\% \\
\hline $\begin{array}{l}\text { Ver o escuchar programas de televisión, } \\
\text { radio, videos musicales, etc. }\end{array}$ & 38.2 & 50 & 55 \\
\hline $\begin{array}{l}\text { Información sobre temas que me } \\
\text { interesan como videojuegos, viajes, } \\
\text { moda, política, etc. }\end{array}$ & 12 & 16.25 & 15.1 \\
\hline $\begin{array}{l}\text { Distribuir las fotos, videos que yo hago } \\
\text { o mis opiniones. }\end{array}$ & 18.4 & 10 & 16.4 \\
\hline $\begin{array}{l}\text { Buscar información para realizar mis } \\
\text { tareas de la escuela. }\end{array}$ & 67.1 & 73.75 & 81 \\
\hline Bajar música, películas o video juegos. & 36 & 41.25 & 48 \\
\hline
\end{tabular}

2 Ibid., p. 56.

$3 C f r$. Anaya Rivas, J. M. "Análisis del uso de Internet y redes sociales de los alumnos de educación media básica en Santa Catarina Ayotzingo", México: JMAR, 2013, p. 36-37. 
Relación de usuarios 2.0...

\begin{tabular}{|l|c|c|c|}
\hline Para relacionarme con gente. & 14.5 & 26.25 & 36 \\
\hline Otras & 5.26 & 0 & 0 \\
\hline
\end{tabular}

Fuente: Anaya Rivas, José Mauricio. "Análisis del uso de Internet y redes sociales de los alumnos de educación media básica en Santa Catarina Ayotzingo", México: JMAR, 2013, p. 36.

Por otro lado, si se toma el caso de una red social como lo son las wikis y en específico el de Wikipedia, el uso que le dan los alumnos de la licenciatura en física puede ser observado en la $\mathrm{Fi}$ gura 4 .

Figura 4. Uso de Wikipedia por los alumnos de la licenciatura en física

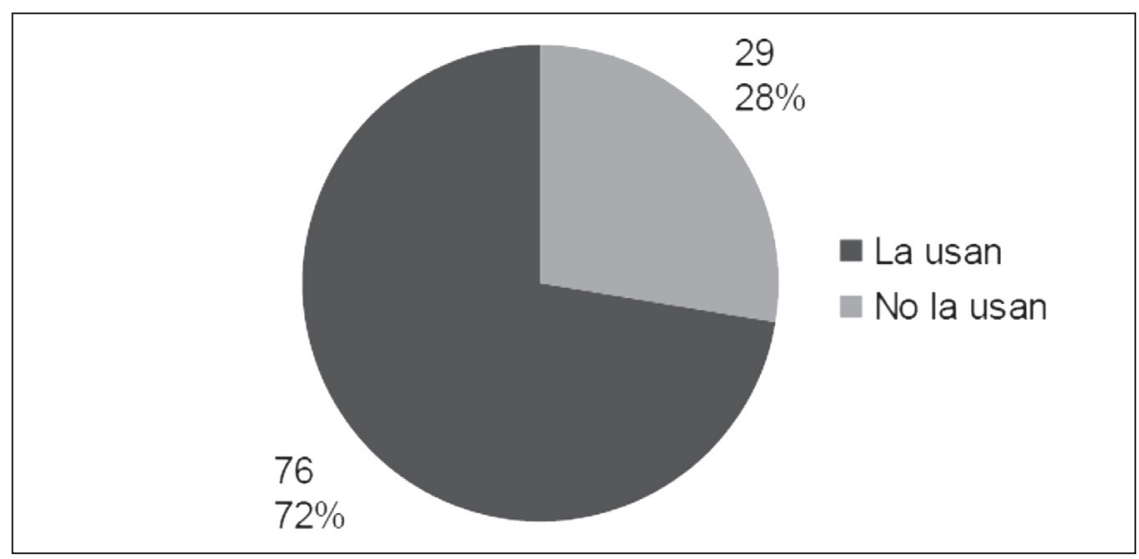

Fuente: Sales Ortega, Iván Santiago. "El uso de Wikipedia por los alumnos de la licenciatura en física de la UNAM", México: ISSO, 2014, p. 34

Los datos anteriores indican que esta herramienta de la Web 2.0 es utilizada con bastante frecuencia y es ahí donde los alumnos de licenciatura buscan y obtienen la información. Otra cosa es indagar con mayor profundidad si es citada en los trabajos escolares que entregan a los maestros, por la confiabilidad de la información que contiene, ya que todos pueden en subir la información que consideren incluir en cada artículo de Wikipedia. 
De igual forma, para otro grupo de alumnos de licenciatura, en este caso de bibliotecología, se puede observar que el uso de la red social Facebook es también de utilidad para la búsqueda y obtención de información. Véase Figura 5.

Figura 5. Uso de Facebook para buscar, obtener e intercambiar información

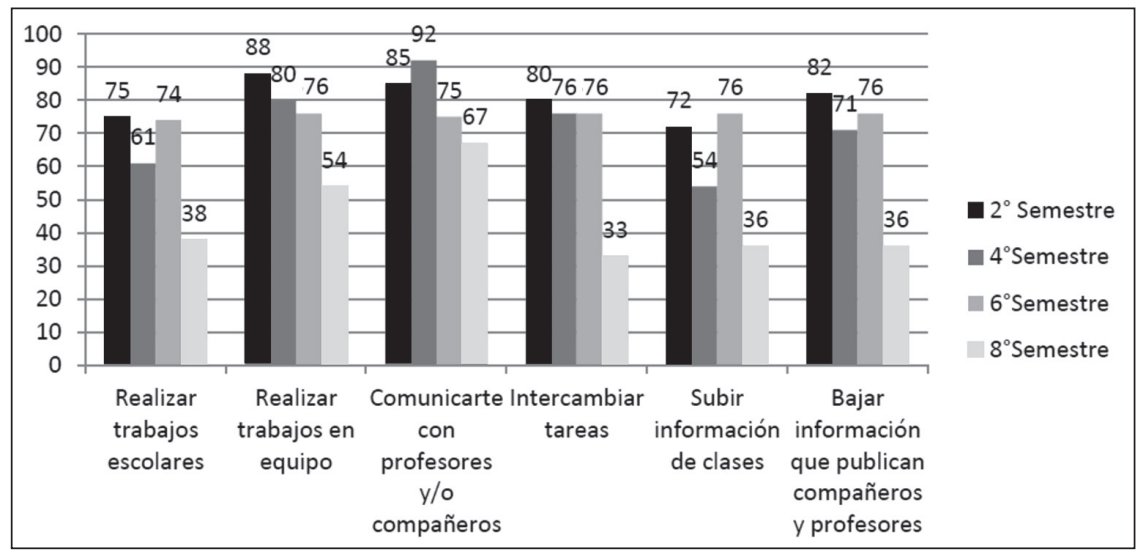

Fuente: Méndez Vergara, Mariana. "Consulta de información académica por alumnos de bibliotecología”. México: MMV, 2014, p. 56

Entonces, los alumnos de licenciatura le ven bastante utilidad a las redes sociales, no sólo para la comunicación sino para la búsqueda y obtención de información académica, la cual es producto de la docencia y la investigación.

Lo anterior se debe al incremento del uso de las nuevas tecnologías, así como al aumento de usuarios de Internet, lo cual ha propiciado que los estudiantes de varios niveles, entre ellos, por ejemplo de educación básica y media básica (primaria y secundaria) hagan uso de las redes sociales no sólo como un medio de comunicación (aunque este fin sea el de mayor peso), sino para la búsqueda de información para la elaboración de los trabajos escolares.

Siguiendo la utilización de las redes sociales y su fácil acceso se tiene, por ejemplo, al Facebook, el cual se coloca en primer lugar 
en varios de los resultados presentados, el segundo sitio lo ocupa YouTube, siendo también un sitio muy popular para los estudiantes para escuchar música, ver videos y opinar acerca de los mismos, además de que éste último no requiere registro de usuario para tener acceso. Esta herramienta de la Web 2.0 se utiliza para obtener información visual y auditiva, por ejemplo, un video histórico sobre la vida de Platón, o sobre la historia de la Grecia clásica, que el profesor de bachillerato les proporciona por correo electrónico o en el muro del Facebook a través de un enlace, el cual posteriormente discute con ellos en clase.

\section{CONCLUSIONES}

A través de los resultados expuestos de las investigaciones llevadas a cabo en diversas comunidades de usuarios de la información: alumnos de secundaria, bachillerato y licenciatura, se puede llegar a las siguientes conclusiones:

- El uso de las redes sociales, como una de las herramientas de la Web 2.0 es sin duda uno de los pilares de comunicación entre diversos sectores académicos estudiantiles y sobre todo, le permite a los jóvenes entablar contacto con familiares, amigos, conocidos y desconocidos sin estar en contacto presencial con ellos.

- El uso de las redes sociales no es solo para un fin de comunicación sino que se tiene la impresión de que crece cada vez más el uso de las mismas para la búsqueda y obtención de la información de corte académico que necesitan diversos sectores sociales, principalmente los alumnos de diversos niveles educativos. El uso de las redes sociales como herramientas de la Web 2.0 está en aumento vertiginoso por las ventajas y posibilidades que puede tener y en que se pueden aplicar. 
- $\quad$ La utilización de las redes sociales como parte de la Web 2.0 tiene ventajas que cada vez se van sumando y entre las cuales se pueden: obtener noticias en tiempo real (no solo con texto, sino también con fotos y con videos), mantener comunicación constante y en tiempo real con sus contactos, aun cuando estos se encuentren en otro uso horario, por ejemplo. Así se encuentra que entre estudiantes de educación media y básica, la principal finalidad del uso de las redes sociales es chatear, seguido por subir fotos, ver videos y con fines de entretenimiento, pero una parte de ese tiempo también es para buscar, localizar y obtener información, así como compartirla a través de estos mismos medios.

- Cabe mencionar que también tiene desventajas por ser una herramienta donde todos pueden participar y subir información y es que la información puede ser equivocada o errónea; agregar a desconocidos como contactos puede llevar a cuestiones de seguridad, privacidad y robo de identidad. Los usuarios jóvenes como los alumnos de primaria o secundaria pueden estar en riesgo, ya que pueden proporcionar información personal o datos confidenciales de índole familiar en sitios de la Web 2.0, los cuales son o pueden ser tan abiertos que cualquiera los puede visualizar.

- También es preciso considerar que el uso de las redes sociales sirve para buscar información, localizarla y obtenerla a través de las diversas herramientas: Facebook, YouTube, Twitter, wikis y otras más. Mucha de esta información es del sitio web de instituciones academicas, pero indudablemente no siempre será el caso.

- Los alumnos de diferentes niveles usan los buscadores, principalmente Google para realizar sus búsquedas de información escolar o van directamente a la wiki más popular, Wikipedia, para obtener la información que necesitan en sus actividades académicas como elaborar su tarea, preparar un examen o hacer los trabajos en equipo y, también, para usarla en su vida cotidiana. 


\section{BIBLIOGRAFÍA}

Anaya Rivas, J. M. "Análisis del uso de internet y redes sociales por los alumnos de educación media básica en Santa Catarina Ayotzingo Mártir". México: JMAR, 2013. Tesis (Licenciado en Bibliotecología y Estudios de la Información) -UNAM.

Fuentes Gatica, L. A. "Análisis de la búsqueda de información académica utilizando la Web 2.0 por los alumnos de la Facultad de Ciencias de la UNAM". México: LAFG, 2014. Tesis (Maestría en Bibliotecología y Estudios de la Información) -UNAM

Guzmán Prieto, E. "El uso de las redes sociales para la búsqueda de información escolar de los alumnos de educación básica en el pueblo de San Gregorio Atlapulco y San Luis Tlaxialtemalco en Xochimilco". México: EGP, 2012. Tesis (Licenciado en Bibliotecología y Estudios de la Información) -UNAM

Méndez Vergara M. "Consulta de información académica en Facebook por los alumnos de bibliotecología". México: MMV, 2014. Tesis (Licenciado en Bibliotecología y Estudios de la Información) -UNAM.

Sales Ortega, I. S. "El uso de Wikipedia por alumnos de la licenciatura de física de la UNAM". México: ISSO, 2014. Tesis (Licenciado en Bibliotecología y Estudios de la Información) -UNAM

Sánchez Flores, C. B. "Uso de los sitios de redes sociales como servicio de la biblioteca universitaria". México: CBSF, 2014. Tesis (Licenciado en Bibliotecología y Estudios de la Información) -UNAM. 
Usuarios 2.0 de la información...

Torres Piñon, O. N. "Uso de herramientas Web 2.0 por los usuarios de la biblioteca central de la UNAM". México: ONTP, 2014. Tesis (Licenciado en Bibliotecología y Estudios de la Información) -UNAM

Vargas Medina, C. R. "Propuesta de guía para implementar servicios en la Biblioteca 2.0". México: CRVM, 2013. Tesis (Licenciado en Bibliotecología) -UNAM. 


\title{
Interactuación 2.0 entre medios de comunicación televisivos y usuarios: uso de redes sociales en medios españoles y mexicanos
}

\author{
Jorge Caldera Serrano \\ Universidad de Extremadura
}

\section{NUEVAS FORMAS DE HACER Y ENTENDER EN LOS MASS MEDIA}

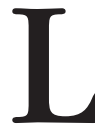

os medios de comunicación se han desarollado como la principal fórmula de acceso a la información y también al entretenimiento para la mayor parte de la sociedad. La televisión ha sido durante décadas la forma habitual de acceder a los contenidos audiovisuales, informativos y de ocio, pero esta realidad está siendo cambiada por la revolución del presente siglo, no sólo por la red sino por las nuevas formas de comunicación e interacción. La Web 2.0 y sus principales herramientas de intercomunicación en la web social han generado un cambio radical. Nuestros jóvenes utilizan la web social para acceder a la información, y por lo tanto, la televisión parece estar perdiendo la supremacía. Tanto es así que en un par de décadas, a este ritmo evolutivo, la red será sin duda la fórmula más utilizada para acceder a la información por parte de la sociedad avanzada.

Ante esta realidad, los medios de comunicación audiovisuales han cambiado sus formas de hacer y entender. Tales medios han puesto sus esfuerzos y sus contenidos en sus plataformas en la red, digitalizando material y facilitando contenidos para que la oferta de programación no sea estática sino que los telespectadores puedan 
visualizar los contenidos cuando quieran y donde quieran, y además, han llevado a cabo una evolución y revolución fundamental: que implica el abandono del modelo unidireccional (de la televisión hacia los telespectadores) y fomentado un nuevo modelo multidireccional (de la televisión a los internautas; y de internautas a otros internautas siendo la plataforma de la televisión la intermediaria) en la cual estamos conectados tanto con la cadena como con otros usuarios.

Los medios audiovisuales se han adaptado a los medios multiformato digitales, a métodos de difusión de contenidos que han superado el tiempo y el espacio, y a la sincronización con el usuario, y ahora son medios dinámicos, abiertos, gracias a la mejora de la tecnología que ha hecho posible una mejor concurrencia en los servidores y una mayor rapidez comunicativa.

$\mathrm{Y}$ de este nuevo paradigma y formas de hacer $\mathrm{y}$ entender la nueva televisión, ha aparecido una clara relación y uso con las redes sociales digitales en red.

Las redes sociales son formas de interacción que cuentan con intercambios rápidos y multidireccionales, entre personas, instituciones y grupos. Unión de individuos con una misma necesidad, con un mismo fin y con ganas de intercambiar información. Y todo ello partiendo de una idea clara: la fragmentación, la creación de subconjuntos y la parcialización de la realidad social atendiendo a cientos de parámetros comunes.

Surgidas a principios de siglo, tales redes han logrado una gran penetración en Internet, y conseguido contar con millones y millones de personas conectadas. Una de las grandes ventajas de las redes sociales es su facilidad de uso, además de que sus requerimientos previos, desde el punto de vista del aprendizaje tecnológico, son prácticamente nulos (Villanueva, 2010).

\section{DELIMITANDO CONCEPTOS}

Existen tren conceptos que deben ser analizados brevemente para comprender mejor cómo se desarrolla la labor en el grupo de in- 
vestigación. Concepto clave es el de Web 2.0, y en una de las aristas del proyecto también lo sería el concepto audiovisual. No obstante, el concepto clave es el de usuario, ya que tanto los servicios planteados en las unidades de información, como en los medios de comunicación, cuentan con el fin inicial y último de que sean utilizados, adquiridos y asimilados por los usuarios.

Web 2.0

Se podría definir la Web 2.0 como la promesa de la visión de la red en un espacio social común, con la capacidad de intercomunicar y generar conocimientos, siendo un verdadero soporte para una sociedad de la información (Fumero y Roca, 2007). Los autores señalan que esa promesa de Web 2.0 se hace cada vez más real en el contexto social y tecnológico, el cual está en permanente proceso de cambio y dinamización. Aunque las empresas relacionadas con la red sufrieron no hace mucho un grave desplome, se está experimentando un claro renacer en la actividad empresarial relacionada con la red.

Existe un evidente aumento en el número de usuarios, de internautas que forman parte de la comunidad, los cuales se rigen bajo principios y valores éticos, que Himanen definió como "ética hacker" (2002), comunidad que se ve incrementada por los "nativos digitales" (Marc Prensky, 2001) nacidos y criados en el nuevo ambiente tecnológico, y de los inmigrantes digitales incorporados a la red en las diferentes fases del proceso de alfabetización tecnológica, con el fin de limar en cierta medida los problemas derivados de la brecha digital.

De esta realidad surge la denominada web de las personas (Web 2.0) frente a la web de los datos (Web 1.0), un fenómeno caótico que se genera a partir de la propia dinámica de un sistema en constante evolución y mutación de la red, de Internet.

Son variados los productos que surgen de la Web 2.0 al ser éste un fenómeno multifacético que aparece en los blogs, los servicios en línea que se relacionan directamente con las redes sociales, el amplio abanico de aplicaciones y los usos sociales (Torres, 2008). 
Al igual que el término 2.0 la web ha calado en los ámbitos empresariales y financieros, también ha tenido su implantación en el ámbito social, calificativo —-social— que se ha incluido a todo lo relacionado con la red siempre y cuando tenga relación con el 2.0 (Guimera et. al., 2012).

\section{Medios de comunicación audiovisuales}

Existe una clara mezcla en los medios, una confusión/fusión generada de forma premeditada con el fin de obtener las mejores ventajas de cada una de las formas de comunicación. Prensa, radio y televisión, todos los formatos están presentes en la web, y además, se ha potenciado sobre manera su vertiente audiovisual, derivada de lo atractiva, cómoda y sencilla que resulta como fórmula de acceso a la información. Por lo tanto es un error hablar de medios de una única naturaleza cuando éstos están presentes en la red.

Todos sobreentendemos que los medios audiovisuales son aquellos que cuentan con información sonora y audiovisual, de forma sincrónica, y difundidos en un único código de tiempo, por lo que se distinguen claramente de la información sonora. No obstante, la imagen en movimiento sin sonido - por definición- no es audiovisual, no obstante se incluye, por supuesto, en estos medios de información.

En definitiva y sin querer profundizar en el concepto "audiovisual”, hay que señalar que vamos a entender como medios de comunicación audiovisual a las instituciones televisivas que vuelcan sus contenidos en la red, pudiendo ser su contenido de diversa naturaleza (Caldera y Arranz, 2012).

\section{¿Usuarios/telespectador/cliente?: ciberespectador}

Resulta un tanto complicado discernir el mejor término para identificar a este tipo de usuario. Inicialmente, la mejor manera de describirlo sería como internauta, si lo identificamos como aquella persona que utiliza la red como forma de comunicación. No obstante, estos internautas cuentan con peculiaridades propias de los medios tradicionales audiovisuales, tales como el carácter de telespectador, 
ya que parte fundamental de los contenidos volcados por los medios es de naturaleza audiovisual, y no sólo audiovisual, sino que es material que se genera para los medios tradicionales y que son volcados en la red sin ningún tipo de manipulación. La red se convierte en un repositorio de videos. La televisión a la carta no es sino la posibilidad de ver aquellos videos que están en la televisión convencional por medio de la red. Ahora bien, el lenguaje audiovisual también se irá modificando, ya que no es igual la difusión por la red que por la televisión. No obstante, las televisiones que sólo emiten por la red y para la red todavía no son una realidad.

Por lo tanto, los consumidores de estos contenidos son internautas con una clara tradición de telespectadores, que además se convierten en clientes, ya sea por el pago de contenidos audiovisuales o por ser los usuarios de publicidad directa en el entorno web, o en la propia emisión.

Pero estos internautas no sólo quieren ser meros espectadores, consumidores de contenidos, sino que desean formar parte de ello de cierta manera, sentirse en una aldea común, de un colectivo que no sólo visualiza sino que también analiza, critica y se apasiona con los contenidos, y para ello necesita comunicarlo. Son los Internautas 2.0 de contenidos audiovisuales. Y sólo vamos a tratarlos como consumidores y comunicadores de estos contenidos, no como generadores de material audiovisual, lo cual es sin lugar a dudas cada vez más importante y determinante. Lo que se desea analizar es cómo los medios de comunicación incluyen herramientas y mecanismos de la web social en el marco de la explotación de sus formatos tradicionales.

El internauta audiovisual cuenta con un doble aprendizaje y/o alfabetización: el tecnológico y el audiovisual (Caldera y Arranz, 2013). Aunque tal y como se ha señalado, los nativos digitales no han sufrido de forma traumática el cambio tecnológico, se han ido adaptando de forma inmediata al uso de las TIC, ausentes para generaciones anteriores. No ha sido un aprendizaje de impacto, sino una adaptación vital en el uso de éstas ya no tan novedosas tecnologías. Igualmente, su adaptación al lenguaje audiovisual ha sido realizada de forma intuitiva, no cómo con las generaciones anteriores en las que el impac- 
to del lenguaje audiovisual hizo que se tuviera que aprender a captar y asimilar mensajes informativos de manera muy distinta. Por lo tanto, los internautas usuarios de los contenidos audiovisuales televisivos han ido implementando de forma natural la utilización de una serie de herramientas tecnológicas y de un mensaje audiovisual que lo ha impregnado todo desde su nacimiento.

Además, existe otra necesidad de adaptación, que ha sido el conocimiento y adaptación a las herramientas de acceso; nos referimos a los dispositivos móviles como a los fijos, que tienen distintas formas de interacción y de accesibilidad derivadas de su tamaño, conexión a la red y la utilización de periféricos para la interacción. No es idéntico el manejo si tratamos la conexión por medio de dispositivos móviles o tablets, que si la interacción se lleva a cabo por medio del teclado (cuántos niños/as intentan actualmente acceder a la información por medio de la información táctil por medio de las pantallas y no por otros periféricos).

Estos nuevos usuarios, a los cuáles está realmente dirigido este nuevo tipo de comunicación televisiva (nativos digitales) han nacido y crecido entre diferentes pantallas: la de la televisión, la del teléfono, la del videojuego, la del ordenador etc., y su forma de comunicación y de entender dicha comunicación debe tener presente siempre este dispositivo y muy especialmente su valor audiovisual.

Queremos aclarar que aunque los medios de comunicación implementan y generan la conexión de redes sociales en sus cadenas y productos audiovisuales pensando en los nativos digitales es evidente que también se adaptan a los inmigrantes digitales que tienen buena capacidad de adaptación y ganas de ello. No obstante, una de las ventajas de las redes sociales es su facilidad de manejo y su potencialidad para generar nuevos adeptos.

Por lo tanto, este internauta consumidor de contenidos audiovisuales no deja de ser en definitiva un telespectador que consume información audiovisual a través de un medio distinto al tradicional (televisión), un cliente de la cadena que puede adquirir y acceder a productos de la propia empresa o facilitados y difundidos por publicistas que usan las plataformas de la cadena, y es un usuario de las tecnologías de la comunicación en línea. Es, por 
lo tanto, un cibertelespectador que se une a la visión continua de información audiovisual por medio de la red, el uso de herramientas de la web social para compartir, analizar y valorar dichos contenidos facilitados por las empresas audiovisuales, tanto entre los cibertelespectadores como con la empresa distribuidora de contenidos.

Las características de estos cibertelespectadores es la suma de los consumidores de productos audiovisuales de forma tradicional, más la de los usuarios de redes sociales. No obstante, queremos destacar una serie de elementos que creemos que distinguen a este tipo de internautas.

- Son consumidores ávidos de contenidos audiovisuales novedosos. Estos cibertelespectadores requieren de forma regular contenidos audiovisuales para consumir. Esperan deseosos el siguiente programa, el siguiente capítulo, y en definitiva, seguir viendo y analizando contenidos novedosos en los que puedan aportar su visión.

- Quieren información audiovisual de forma regular. Además de requerir contenidos audiovisuales, éstos son requeridos de forma sistemática. Es importante por parte de la empresa no defraudar ni decepcionar a tan apasionados y activos seguidores, por lo que en caso de posibles pérdidas en dicha rutina en la difusión de contenidos, la empresa deberá anunciarlo con la debida antelación y explicar los motivos.

- Son críticos y apasionados. Los cibertelespectadores son muy activos en las redes sociales propias de dicho medio, así como en la utilización de blogs si estiman que dicho medio y formato es útil para conocer y difundir información sobre aquel elemento en común que los apasiona. Por lo tanto, la importancia del blog dependerá especialmente de la validez del bloguero como fuente de información. Son críticos con los contenidos y muy apasionados en la información vertida. Por lo tanto, es muy necesario que en las empresas audiovisuales exista la figura del Community Manager para gestionar el flujo de información de todas las redes sociales. 
- Son fieles y tienen sentido de comunidad. Se sienten miembros de la Aldea Global, aunque a pequeña escala y con elementos comunes que los diferencian. Igual que existe la Aldea Global de los amantes del fútbol que se conectan a la vez para visualizar una final de la Copa del Mundo, también existen comunidades de miembros de redes sociales que tienen un interés común: compartir información, a través de un producto audiovisual que los y las apasiona.

- Usan de forma regular las redes sociales. Estos cibertelespectadores son activos en las redes sociales de forma general en todos los ámbitos de su vida. Es decir, que la conexión para disfrutar de estos intereses comunes no es más que otro elemento interesante de su perfil en la red social, lo que no quita que la utilicen para otros fines. El número de usuarios de redes sociales se ha disparado de forma exponencial, y el tiempo de actuación en ellas no para de crecer, por lo tanto es entendible el hecho de que no las utilicen únicamente para un aspecto determinado de la vida, como pudiera ser la conexión con personas interesadas en un producto audiovisual, sino que es una forma de conectarse con amigos y conocidos, como mecanismo para establecer interrelaciones profesionales, educativas, deportivas, lúdicas, etc.

Existe además otro elemento clave, la información que puede extraer la empresa audiovisual de la interconexión y comunicación con estos cibertelespectadores es importante, y puede dar pautas para determinar posibles nuevas vías de negocio, o determinar el potencial de nuevos productos. En definitiva, pueden identificarse las modas y también la viabilidad o no de productos audiovisuales. Evidentemente esta información deberá relacionarse con otros parámetros como son los datos de audiencia, tanto en emisión tradicional como de visitas a la red, y otras herramientas tradicionales como las encuestas. En definitiva, las empresas audiovisuales deberán estar alertas a la información facilitada e intercambiada por medio de las redes sociales, información que será útil tanto para los publicistas como 
para los guionistas e incluso para los programadores de las parrillas televisivas.

Para lograr muchos de los elementos descritos en este apartado es necesaria la existencia de la figura del Community Manager (Marquina, 2013) o del equipo de trabajo que lleve a cabo la labor de controlar el flujo informacional en las redes sociales, controlando así tanto la imagen de marca de la propia empresa, como las de los diferentes productos con los que cuenta la cadena. Además, parece inevitable contar con esta figura para dar respuesta a los muchos requerimientos que los cibertelespectadores les hacen a los medios a través de las redes sociales. Por lo tanto, hay en todo esto una doble funcionalidad: contestar a los requerimientos y crearlos.

\section{Metodología Y OBJETIVOS DE ANÁlisis}

El objetivo del presente estudio es entender mejor el uso de las redes sociales por parte de los principales medios de comunicación audiovisual de España y México e intentar así evidenciar la hipótesis de partida: el cambio por medio del uso de plataformas web de métodos de herramientas de comunicación unidireccional por las de uso multidireccional.

Por lo tanto, el objeto de estudio serán las web de los medios de comunicación de los países indicados y la existencia de información -y la posterior confirmación- del uso de redes sociales como forma de interconectarse con los internautas de medios audiovisuales.

Para identificar cuáles son los medios de comunicación más importantes se ha utilizado para España el Estudio General de Medios (http://www.aimc.es/-Datos-EGM-Resumen-General-.html), el cual nos define las cadenas más vistas en España. Así, para determinar cuáles son los medios analizados, en el caso español, se han considerado aquellos que cuentan con mayor índice de audiencia $\mathrm{y}$, por lo tanto, de cuota de pantalla en los principales productos audiovisuales de la cadena. 
El modelo mexicano de televisión es algo distinto, siendo diversa la forma de acceso y el tipo de cobertura de los medios. No existen estudios claramente delimitados de audiencias que sean accesibles con facilidad, salvo los de la empresa Ibope AGB (https://www.ibopeagb.com.mx) que ofrece sus servicios a empresas audiovisuales. Al carecer de estudios exhaustivos de audiencia, tal y como se realizan en España, hemos tomado como válidos los realizados por la empresa indicada con anterioridad, aunque el entramado empresarial mexicano y las formas de difusión son distintas al mercado europeo, y más semejante al estadunidense.

Televisa y TV Azteca tienen un modelo de televisión concesiona$\mathrm{da}$, y cuentan con diferentes frecuencias y cadenas (cuatro y tres, respectivamente), que hacen de estos dos grupos audiovisuales los más importantes del país. Aunque de menor importancia y alcance, los canales TV UNAM y Canal 22 emiten por medio de televisiones estatales afiliadas, y por eso pueden ser consideradas como canales de emisión nacional. Un análisis del sistema televisivo mexicano lo tienen en la siguiente dirección web: (http://es.wikipedia.org/wiki/Ane xo:Canales_de_televisi\%C3\%B3n_en_M\%C3\%A9xico).

Los medios españoles identificados como más importantes son:

- Televisión Española (www.rtve.es)

- Tele Cinco (www.telecinco.es)

- Antena 3 TV (www.antena3.com)

- La Sexta TV (www.lasexta.com)

Cabe señalar que hemos unido las audiencias de las dos cadenas de Televisión Española así como la suma de las cadenas Tele Cinco y Cuatro, recientemente unidas en una única cadena televisiva desde el punto de vista del accionariado. Aunque Antena 3 TV y la Sexta TV también se han fusionado recientemente, se estima interesante el análisis por separado de ambas cadenas, ya que las dos son muy activas en redes sociales y cuentan con estructuras web diferentes. 
Los medios mexicanos identificados como más importantes son:

- Televisa (www.televisa.com)

- TV Azteca (www.tvazteca.com)

- TV UNAM (http://www.tvunam.unam.mx)

- Canal 22 (http://www.canal22.org.mx)

Otro aspecto metodológico importante es identificar cuáles son las principales herramientas de las redes sociales que deberían ser identificadas. Para ello, hemos analizado la literatura existente, y hemos tomado como base el estudio realizado en la Web de Empresa 2.0, en su blog (http://www.webempresa20.com/blog/456-las-40-re des-sociales-mas-populares.html) donde se nos plantea un rango que incluye las 40 redes sociales más interesantes y populares por medio de una metodología sencilla y con parámetros claros. En dicha metodología se tienen en cuenta el número de usuarios, el ranking de Alexa y el Page Rank de Google, que le da la mitad del valor al número de usuarios, y un $25 \%$ de valor a las otras dos variables que miden la importancia y popularidad de un sitio web.

Una vez depurada la lista, ya que, por ejemplo, cada vez es más importante la presencia de redes sociales chinas y otras muchas que realmente no son generalistas sino profesionales, hemos determinado las siguientes herramientas como las tres principales herramientas sociales.

\begin{tabular}{|c|c|c|}
\hline Nombre & Url & Usuarios \\
\hline Facebook & www.facebook.com & +900 millones \\
\hline Twitter & twitter.com & +500 millones \\
\hline Google+ & plus.google.com & +100 millones \\
\hline
\end{tabular}

Somos conscientes de que Twitter no es realmente una red social sino un microblogging, pero su importancia y forma de distribución es tan potente que hemos querido analizarla. Además, su desarrollo y aumento en lo que respecta al número de usuarios hace imprescindible su análisis. 
Una vez que se han identificado los principales medios y las principales herramientas, se ha procedido a darlas de alta en estas herramientas y a buscar e identificar los medios. Además, y en último lugar, se han consultado las web de los medios para:

- Analizar la visibilidad y ergonomía de estos elementos.

- Identificar si están presentes para diferentes secciones y cuáles son aquellas en las que se facilitan.

- Y si existen además como material no generado por la cadena pero sí adquirido (material de ficción).

Análisis de los principales medios audiovisuales españoles

\begin{tabular}{|l|c|c|c|c|}
\hline \multicolumn{1}{|c|}{ España } & TVE & Antena 3 TV & Tele Cinco & La Sexta \\
\hline Facebook & sí & sí & sí & sí \\
\hline Twitter & sí & sí & sí & sí \\
\hline Google + & sí & sí & sí & sí \\
\hline
\end{tabular}

(Se indicará sí si cuenta con al menos un perfil o un enlace para compartir desde la web de la cadena)

\section{Televisión Española}

La presencia en Facebook de TVE no sólo se ciñe al enlace del perfil de la cadena, sino que podemos encontrar un perfil distinto para cada una de las cadenas que componen TVE (internacional, TVE1, TVE2, Clan, etc.) además de perfiles de los programas más importantes y las series más representativas de la cadena. Por lo tanto, existe una clara presencia de esta cadena, además de fragmentar también a los seguidores sobre los perfiles concretos de sus principales productos audiovisuales.

Los enlaces a Facebook están presentes en la primera página de la cadena y en las diversas series, y en las noticias - al finalse ofrece la posibilidad de compartirlas por medio de Facebook.

La opción de twittear la información volcada en la web de la cadena es una realidad para todas las noticias presentes. Esta opción es claramente mostrada al final de cada noticia. Además, la cadena 
tiene perfiles dados de alta para cada una de sus cadenas y para los servicios informativos.

TVE cuenta con un perfil para Google+ por medio del cual distribuye información. No ofrece la opción de acceso o intercambio por medio de otras redes sociales.

\section{Antena 3 TV}

Esta cadena cuenta con un claro perfil en Facebook, y presencia en la web para poder ir a este perfil. Y además de poder enlazar vía Facebook con las noticias, también cuenta con perfiles concretos para algunas de las secciones, como es el caso de la Fórmula 1.

La presencia de Twitter es real pero no extendida. Sí cuenta con perfil para la cadena y para los informativos de su programa estrella que es la emisión de la Fórmula 1, pero no muchos más perfiles. No obstante, en la mayor parte de la información se ofrece la opción en la web para poder retwittear.

Sobre Google+ hay que señalar su presencia tanto como método de difusión en cada una de las noticias de la cadena, como por medio de perfiles concretos relacionados con la cadena, con la sección de noticias y con la sección de internacional.

Antena 3 TV, cuenta además con presencia en redes sociales nacionales como Tuenti y otras formas de compartir como "Menéame" y YouTube.

Cabe señalar que, realizando scroll (desenrollar) en su larga página principal, la cadena señala que está presente en Facebook, Twitter, Tuenti y YouTube, ofreciéndolos como un activo importante de intercomunicación con sus telespectadores. Además las noticias pueden ser compartidas por: Facebook, Twitter, Tuenti, Google+, Menéame y Messenger.

\section{Tele Cinco}

La página principal de la cadena Telecinco — parte de un Grupo de Comunicación mucho mayor - facilita el acceso tanto a los per- 
files de Facebook, Twitter, Tuenti como la opción de acceder a noticias vía RSS (Sindicación o Agrupación Realmente Fácil)

Prácticamente todas las noticias facilitan la opción de compartir por las dos principales redes sociales (Facebook y Twitter), además de facilitar la información para el intercambio del video.

Sobre perfiles en Facebook de la cadena, es importante señalar que se encuentra el perfil general de la cadena, así como el de los informativos, cine y matinal. Además, algunos programas y series como "Gran Hermano" o "La que se avecina" cuentan con sus propios perfiles.

Al igual que en Facebook, los perfiles en Twitter son evidentes, y prácticamente duplican los de la herramienta anterior, e incluso aumentan el número de perfiles. Además facilitan los perfiles de algunos presentadores y personajes relacionados con la cadena.

Sobre la presencia en Google + se debe señalar que es escasa y tiene sólo un único perfil para toda la cadena por medio de la cual le da la información a sus seguidores.

\section{La Sexta TV}

No presenta información en la primera página sobre las redes sociales con las cuales se puede interactuar con la cadena. No obstante, para Facebook sí cuenta con perfiles generales de la cadena así como con la sección de deportes. Además, tiene perfiles con sus programas estrellas como "El Intermedio", "Al rojo vivo", el "Club de las Comedias"; es decir, con todas las producciones asociadas.

La cadena cuenta con perfiles en Twitter, tanto de la cadena como de secciones como meteorología, deportes, noticias, así como sobre los personajes más importantes de la cadena. Además, cada noticia puede ser retwiteada.

Sobre la opción de Google+ hay que señalar que no existe la opción de contar con perfiles propios de Google+, aunque sí existe la opción de compartir, por medio de esta herramienta, sus diversas informaciones. 
Sin presencia en la web general, después en la organización por programas principales se da la opción de relacionarse por medio de Facebook, Twitter, Google+, Menéame y Delicious.

Análisis de los principales medios audiovisuales mexicanos

\begin{tabular}{|l|c|c|c|c|}
\hline \multicolumn{1}{|c|}{ México } & Televisa & TV Azteca & TV UNAM & Canal 22 \\
\hline Facebook & sí & sí & sí & sí \\
\hline Twitter & sí & sí & sí & sí \\
\hline Google+ & sí & sí & sí & no \\
\hline
\end{tabular}

Televisa

En la página principal del grupo de comunicación de Televisa no se hace referencia a redes sociales de ningún tipo. Pero en algunas opciones que van apareciendo en pantalla sí se ofrece la posibilidad de acceder a perfiles en Facebook y Twitter; ejemplo de ello es el programa "La Voz... México". Además de ello, la cadena cuenta con un foro y un chat propio.

La web está organizada en cuatro grandes secciones (noticiarios, deportes, entretenimiento y especiales), todas estas opciones tienen la opción de ir a los perfiles de Facebook y Twitter, y además, de ser seguidores de sus perfiles.

Respecto a perfiles, en Facebook existen para el Grupo Televisa, deportes y noticiarios, así como para las cadenas regionales (Televisa Guadalajara).

Sobre Twitter, cabe señalar que se tienen perfiles del grupo, de los deportes y de los noticiarios y especiales, así como para presentadores y personal conocido de la cadena.

Sobre Google+ se puede decir que aunque no aparece claramente la opción de compartir por medio de esta herramienta, sí se cuenta con perfiles concretos en la plataforma. No obstante, no parece una herramienta muy usada. 
Usuarios 2.0 de la información...

TV Azteca

Tanto al principio como al final de la web del Grupo TV Azteca existe la opción de hacerse seguidor de la cadena tanto por Facebook como por Twitter. Esta opción está en un lugar preferente y además también se encuentra al final de la página.

La mayor parte de la información puede ser twiteada por medio de la web, y algunas secciones cuentan además con la opción del enlace de Facebook.

Sobre perfiles, vale señalar que cuentan con ellos en Facebook para el perfil general así como para TV Azteca de otras regiones. No aparece en muchas secciones la opción de Facebook.

Sobre Twitter cabe señalar que existen escasos perfiles, sólo el general, el del programa y el de personajes conocidos de la cadena.

Sobre perfil en Google+ se debe comentar que sólo aparece el perfil de la cadena.

\section{TV UNAM}

La televisión de la Universidad Nacional Autónoma de México cuenta en su página principal con la posibilidad de acceder a los perfiles de la cadena tanto por medio de Facebook como de Twitter, y ofrece igualmente enlaces a videos de YouTube. Este es el gran fuerte de la web de una televisión universitaria, una televisión bajo demanda y que cuenta con sus principales recursos audiovisuales educativos.

Realizando la búsqueda en Facebook, encontramos el perfil general de la cadena, así como de otros grupos de seguidores, pero no cuentan con perfiles diferenciados ni para secciones ni para programas.

Igualmente cuenta con perfil general en Twitter.

Sobre Google+ conviene señalar que no cuenta con un perfil propio (de la cadena de televisión) sino que distribuyen la información sobre ella por medio de un perfil genérico denominado CULTURA UNAM. 


\section{Canal 22}

Esta cadena cuenta con una web inicial simple y extremadamente intuitiva. Tanto es así que es escasa la información sobre la cadena, lo cual la separa del resto de las webs analizadas, y en muchos casos, está sobresaturada de contenidos. En esta misma página inicial, y de forma prioritaria, Canal 22 ofrece la posibilidad de acceder a los perfiles de la cadena de Facebook, Twitter y también de YouTube. Esta sencillez estructural sigue presente a lo largo de toda su web organizada, atendiendo el alcance de la señal. Siempre y en todo momento se ofrece la opción de poder conocer los perfiles de Facebook y Twitter, sin embargo no aparece claramente la opción de compartir por medio de estas herramientas.

Sobre perfiles en Facebook del Canal 22 se debe indicar que tan sólo se cuenta con el principal de la cadena, al igual que en Twitter que también está presente con un único perfil. Sin embargo, no está presente en Google+.

\section{UTILIZACIÓN DE LAS REDES SOCIALES EN LAS CADENAS ANALIZADAS}

En el punto anterior, se ha analizado la presencia de las principales herramientas de las redes sociales (Facebook, Twitter y Google+) en las principales cadenas de España y de México. No obstante, la existencia o no de estas herramientas no determina su uso desde un punto de vista cuantitativo ni cualitativo.

Es imposible determinar lo anterior de forma clara y unívoca, y mucho menos estandarizar el método y explotación de las redes sociales que hacen estas cadenas, debido a que cada una de ellas la utiliza de forma diferente. Algunas de ellas cuentan con una única herramienta para toda la cadena, otras para programas concretos, y otras para productos generados por entidades externas a la propia cadena (productoras audiovisuales), por lo que es complicado cuantificar su uso más allá de lo determinado con anterioridad. Además, no siempre está presente el ¿̨historial? de mensajes ni tampoco un 
contador, por lo que más allá de la información aportada por la web, que además es actualizada constantemente para así hacer más ágiles las conversaciones en las redes sociales, no contamos con información para llevar a cabo un análisis cuantitativo.

Pero si esto es cuantitativamente complicado, el análisis cualitativo también lo es. Sólo se basa en el análisis del experto y en la observación directa que del uso de la misma realizan los usuarios y el equipo de Community Manager de la propia empresa.

No obstante, y siendo conscientes de lo complicado que resulta realizar un estudio exhaustivo y riguroso por medio de la observación, la antropología social y cultural ha utilizado esta técnica como método de recolección de datos para su posterior sistematización y la redacción de resultados. La interacción de las personas por medio de las redes sociales no deja de ser el análisis de una red social y de su comunicación, donde cambia el entorno y los métodos de acceso a la comunicación; no obstante, es sólo un elemento potencialmente analizable por la antropología o por otras ciencias. Con todo lo anterior se desea indicar que, aunque la observación y el análisis directos de un conjunto de individuos no deja de ser de difícil extrapolación, se trata de una metodología utilizada y adaptada para obtener resultados en un entorno real y cerrado, como es el uso de las redes sociales en los medios de comunicación.

Por eso, partiendo de dicho análisis, hemos detectado una serie de elementos que intentamos sistematizar a la vista de los resultados obtenidos tras el análisis de las diferentes cadenas y del uso de las redes sociales.

- $\quad$ Primero.- Existe un mayor uso por parte de las redes sociales en los medios audiovisuales en España. Dicho uso se deriva de que existe una mayor potencialidad para el uso al ser su presencia sensiblemente mayor que en las cadenas mexicanas. Esta realidad viene marcada en buena parte por la realidad empresarial de las cadenas televisivas españolas y de las mexicanas, en el sentido de que en España existe mayor competitividad y mayor tradición en el uso de redes sociales en los medios televisivos. No obstante, esta brecha 
está siendo eliminada de forma drástica, lo que se observa en la utilización dispar por parte de las empresas televisivas mexicanas: mientras que en alguna de ellas su utilización es muy escasa, en otras están al mismo nivel que las principales televisiones españolas.

- $\quad$ Segundo.- La herramienta más utilizada por las televisiones como método de interacción con los usuarios por medio del uso de redes sociales es Facebook (Van Dijck, 2012), lo cual no deja de ser una paradoja desde el momento que se observa una tendencia en el estancamiento de usuarios de esta red social, frente a la utilización de otras como Twitter. No obstante, el uso de otras redes sociales también está presente en alguno de los medios de comunicación. La estandarización y familiaridad del usuario con esta herramienta, no ya tan novedosa, la hace especialmente atractiva y potente, aunque volvemos a señalar que los gustos y hábitos de los jóvenes usuarios, sobre todo, tienen una tendencia distinta, por lo que las empresas audiovisuales deberán potenciar la utilización de Twitter (Highfiled, 2013) en detrimento de Facebook, si desean estar conectados con sus cybertelespectadores.

- Tercero.- Fragmentación de la audiencia en las redes sociales. Esta tendencia es una realidad en la mayor parte de las cadenas, tanto en la tradicional como en línea. Se intenta llegar a los cybertelespectadores por medio de la especialización y de la individualización. No a todos los cybertelespectadores les interesa el mismo tipo de contenidos, de ahí la necesidad de fragmentar dicha audiencia y también a las comunidades en las redes sociales a partir de gustos, aficiones y/o, en definitiva, a una identidad común. Para ello, existe una división entre los formatos, teniendo cada uno de ellos una red social para interconectarse. En resumen, sólo se trata y se recibe información sobre aquellos aspectos que le interesan al usuario, y no tiene éste que recibir información de todos los productos de la cadena. Posteriormente veremos cómo existen productos audiovisuales especialmente seguidos, lo que se potencia igualmente con redes sociales concretas para éstos, donde los 
internautas se sienten más seguros y cómodos al utilizar un lenguaje común y tener las mismas referencias y antecedentes.

- Cuarto.- En algunas cadenas se observa claramente la figura del Community Manager, quien coordina en muchos casos estas redes sociales. Igualmente a veces éste se convierte en un "censor" de algunos comentarios o ataques directos entre usuarios o a la cadena. Además, este Community Manager es igualmente un generador de opinión y en muchos casos es el quien marca las pautas e incentiva las líneas de debate. Debemos recordar que este perfil profesional desea potenciar la red social con el fin de publicitar los productos audiovisuales. No obstante, se debe tener cuidado ya que los usuarios quieren ser absolutamente libres, por lo que si observan una sobredirección de la red esto puede ser contrario a los intereses de la cadena y traducirse en abandonos o inactividad.

- Quinto.- En aquellos casos en los que se cuenta con una única herramienta de red social para la cadena - de lo cual hemos descrito algunos casos existentes en la muestra estudiada - la utilización de ésta es muy genérica. Su uso suele ser para consultar cuestiones concretas de algunos programas como para interconectarse o para tratar información específica; es decir, el hecho de que únicamente exista una red para el análisis de todos los productos (en contraposición a la fragmentación) no se traduce en hablar de cuestiones generales, sino que los propios usuarios al final llevan los diálogos a cuestiones de productos concretos.

- Sexto.- Las redes sociales son utilizadas para tratar sobre elementos concretos de la cadena, ya sea sobre una serie, sobre una película que se emitirá o que fue emitida, o un capítulo concreto de una emisión seriada. No obstante, pueden llevarse a cabo debates en las redes sociales sobre algún personaje en concreto, o incluso, sobre noticias aportadas por los servicios informativos, aunque realmente los cybertelespectadores son mucho más activos en productos de ficción o de entretenimiento que en programas informativos. 
- Séptimo.- De herramientas anteriores como foros y chats se utilizan su adaptaciones de las redes sociales para un tipo de uso con el que se consigue una gran interactividad y transito de mensajes. Esta fórmula no es otra que el contactar con actores, actrices o periodistas, que son caras conocidas de la cadena. Estos íconos, en algunos casos, se conectan a estas redes sociales para compartir información o contestar preguntas de los cybertelespectadores, lo cual genera un número elevado de transacciones en la red. El contacto con estos personajes son las interacciones con mayor número de relaciones en menor tiempo.

- Octavo.- Los deportes siempre son un caso especial. La tribu deportiva siempre es fiel y activa. Las diferentes cadenas suelen agrupar las redes sociales en torno a un fenómeno mediático deportivo, y sobre este evento aglutinan un gran número de relaciones e interacciones por medio de las redes sociales. Ejemplo paradigmático es la Fórmula 1 en una cadena española. Derivado de contar con los derechos de explotación del Campeonato del Mundo así como buenas relaciones publicitarias con los equipos, y especialmente contar con un piloto puntero y mediático, el medio lleva a cabo una agresiva campaña en cada una de las competencias, aportando información y contacto con los periodistas (muy populares y reconocidos) así como con diferentes expertos y pilotos. Aunque el uso de las redes sociales es irregular, ya que no se realizan importantes cambios en época de descanso de la competencia, sí son muy activas durante el campeonato, siendo además una plataforma importantísima de publicidad tanto directa como indirecta.

Se ha intentado sistematizar los aspectos cualitativos destacados tras el análisis y utilización de estas redes sociales por parte de las empresas audiovisuales. Queda claro que existe una rápida evolución en su utilización y uso, de ahí que estos resultados pueden quedar obsoletos con una rapidez trepidante. Los cambios, las modas, la tecnologías son elementos que funcionan como resorte para la evo- 
Usuarios 2.0 de la información...

lución en el uso e interacción de las redes sociales, las cuales lejos de ser una moda pasajera parecen haber venido para quedarse durante mucho tiempo, siempre adaptándose a una evolución constante.

\section{CONCLUSIONES}

Aunque a la vista de las tablas-resumen en las cuales se muestra la utilización de las diferentes herramientas de redes sociales pudiera estimarse que éstas manejan las cadenas de televisión, y pudiera llegarse a la conclusión de que las cadenas cuentan con ciertas características idénticas en el uso y distribución de contenidos por medio de las redes sociales, dicha idea sería falsa. Es cierto que prácticamente todas las cadenas utilizan o cuentan con perfiles para comunicar y difundir contenidos por medio de las tres plataformas estudiadas (Facebook, Twitter y Google+) aunque la forma de utilización y el número de recursos no son para nada idénticos.

Existen cadenas que realizan un mayor esfuerzo en los aspectos ergonómicos y formales para poder integrar a las redes sociales en la distribución de sus contenidos (Televisa, Antena 3 TV y La Sexta), que cuentan además con la facilidad de compartir información de sus páginas web y han logrado establecer destacados perfiles en las redes sociales.

También es interesante destacar que existen dos claras herramientas utilizadas y estandarizadas para todas las plataformas televisivas, como son Facebook y Twitter, estando muy presentes estos recursos para hacer su enlace con las web. Además, podemos afirmar la existencia de una tendencia clara donde Twitter se constituye como la red social de intercambio de información más rápida y con mayor crecimiento, por encima de Facebook, lo que se deriva seguramente del hecho de que los usuarios de Twitter son mucho más activos que los de Facebook, observándose por tanto un cambio en la tendencia de la primera a obtener un mayor número de usuarios.

Además, se observa el arranque de Google+ como herramienta de intercambio, pero sólo se encuentra en un primer estadio de in- 
cursión, ya que son escasos los perfiles si los comparamos con las otras dos plataformas, siendo en casos destacados su presencia simbólica o testimonial por medio de un único perfil general y sin posibilidad de enlace desde la web.

También hemos identificado que algunas de las cadenas cuentan, además, con el uso de otras redes sociales a parte de las analizadas, y que también han sido nombradas en el análisis de cada una de ellas. Cabe destacar el esfuerzo en esta línea de Antena 3 TV, la Sexta, y Televisa siendo ésta última la única que aporta su propio foro y chat para el intercambio de información con sus telespectadores.

Tuenti es la red social más utilizada después de las dos analizadas con más profundidad, para el caso de las web españolas, debido a que es una red muy potente en la península ibérica. Al igual que Menéame que también repite su utilización en varias web.

En México no son utilizadas otras redes sociales propiamente dichas, aunque sí se ha detectado este uso y presencia en YouTube.

Si realizásemos una comparación entre los esfuerzos realizados por las web españolas y mexicanas, la primera conclusión sería clara: no existen grandes diferencias por países, sino por cadenas, peculiaridades que vienen marcadas por el modelo de negocios. Si se quisiera realizar un ranking por el uso, explotación e intercomunicación - vía web como por perfiles- encontraríamos tres grupos: aquellos que actualmente apuestan claramente por la integración y difusión de las redes sociales (Televisa, Antena 3 TV y La Sexta), aquellas cadenas que cuentan con la presencia en redes sociales aunque su apuesta no sea tan decidida (TV Azteca, TVE y Telecinco), y en último lugar las cadenas que aún deben implementar esfuerzos en materias de comunicación por medio de las redes sociales (TVUNAM y Canal 22). No obstante, parece oportuno señalar que tanto TVUNAM como Canal 22 cuentan con organización, financiación, fines, objetivos y misión tan distintas al resto de cadenas que seguramente la comparación no sea equiparable, ya que el resto de canales analizados son grandes cadenas y grupos de canales que luchan por la audiencia y por ingresos cuantiosos por medio de la publicidad. 
Por lo tanto, y en resumen, cabe señalar los grandes esfuerzos de las cadenas de televisión tanto mexicanas como españolas por estar presentes en las redes sociales, siendo conscientes sin embargo, de que es éste un método eficaz y eficiente para lograr la intercomunicación con los nuevos telespectadores. Facebook y Twitter son, sin lugar a dudas, las herramientas más extendidas, en tanto que Google+ va obteniendo cada vez mayor número de usuarios, y que esta tendencia se está transformando también en las cadenas televisivas.

Este nuevo método de comunicación entre los medios y sus telespectadores-internautas, seguidores es una realidad hacia la que los medios deben encaminar sus esfuerzos, ya que los nativos digitales de nuestra sociedad cada vez utilizarán más la red y menos la televisión como método de obtener información. Será necesario, por tanto, adaptar la televisión a estos nuevos métodos, y ser conscientes de que hemos de pensar en los usuarios como una Realidad 2.0

\section{Reconocimientos}

Trabajo realizado en el marco del proyecto de investigación "Usuarios 2.0 de la información audiovisual y textual", que cuenta con el Dr. Juan José Calva González como investigador principal y está financiado por el Instituto de Investigaciones Bibliotecológicas y de la Información de la Universidad Nacional Autónoma de México. 


\section{BIBLIOGRAFÍA}

Caldera-Serrano, J. y P. Arranz Escacha, (2012), Documentación audiovisual en televisión. Barcelona: EPI/UOC. (2013), "New Documentary Selection Methods Arising from Digital Information Systems Employed in Television”. En Investigación Bibliotecológica, 27 (60), pp. 15-26.

Fumero, A. y G. Roca, (2007), Web 2.0. Madrid: Fundación Orange.

Guimera, R., A. Llorente, E. Moro y M. Sales-Pardo, (2012), "Predicting Human Preferences Using the Block Structure of Complex Social Networks". En Plos One, vol. 7, núm. 9, pp. 1-8.

Highfiled, T., S. Harrington y A. Bruns (2013), “Twitter as a Technology for Audiencieng and Fandom: The \#Eurovision Phenomenon". En Information Communication E Society, vol. 16, núm. 3, pp. 315-339.

Himanen, P. (2002), La ética de hacker. Barcelona: Destino.

Marquina-Arenas, J. (2013), Plan Social Media y Community Manager. Barcelona: EPI/UOC.

Noguera Vivo, J. M. (2010), "Redes Sociales como paradigma periodístico. Medios españoles en Facebook". En Revista Latina de Comunicación Social, 65, pp. 176186. Disponible en: <http://www.revistalatinacs.org/10 /art/891_UCAM/13_JM_Noguera.html>. Fecha de consulta: $1^{\circ}$ de junio de 2011 .

Prensky, M. (2011), Enseñar a nativos digitales. Madrid: Ediciones SM. 
Torres Vargas, G. A. (2008), "El uso del término redes sociales y algunas confusiones". En Investigación Bibliotecológica, vol. 22, núm. 46, pp. 41-57.

Van Dijck, J. (2012), "Facebook as a Tool for Producing Sociality and Connectivity", en Television \& New Media, vol. 13, núm. 2 , pp. 160-176.

Villanueva, G. y M. de la L. Casas Pérez (2010), "E-competencias: nuevas habilidades del estudiante en la era de la educación, la globalización y la generación del conocimiento". En. Signo y Pensamiento, vol. 29, núm. 56, pp. 124-138. 


\title{
Dificultades a las que se enfrentan las comunidades indígenas para ser consideradas usuarias 2.0
}

\author{
César Augusto Ramírez VelázQuez \\ Universidad Nacional Autónoma de México
}

\section{INTRODUCCIÓN}

\begin{abstract}
71 presente trabajo tiene como objetivo ofrecer una perspec4 tiva de la problemática a la que se enfrenta un alto porcentaje de las comunidades indígenas para ingresar a Iinternet y utilizar los servicios de la Web 2.0, así como indagar qué tanto afecta la integración de las tecnologías de la información y la comunicación (TIC) a estas comunidades que cuentan con recursos para incluirlas en su vida diaria, y convertirse, a su vez, en Usuarios 2.0.

Las comunidades indígenas en México no han podido evitar el embate impuesto por desarrollos de los medios de comunicación y sistemas de información que derivan de las Tecnologías de Información y Comunicación (TIC). Ubicados en los diversos confines del territorio nacional, en condiciones sociales, económicas, culturales y de cualquier otro orden disímbolas, estos grupos han sucumbido a los golpes de la comercialización de productos a través de medios masivos que se han apoderado del comercio, de la difusión y la divulgación de los diversos productos tecnológicos que han inundado el mercado nacional.
\end{abstract}


Una de las herramientas que ha traído esta marea de TIC es la red Internet, que le ha dado al ser humano una nueva visión del manejo de las comunicaciones entre individuos, comunidades y países, y que en la segunda mitad del siglo XX, junto con otras herramientas tecnológicas, le abrieron paso a la globalización del conocimiento, de la economía y de la cultura, entre otros aspectos.

En la Cumbre Mundial de la Sociedad de la Información, celebrada en Túnez del 16 al 18 de noviembre de 2005 en relación con los indígenas, el "Programa de Acciones de Túnez para la Sociedad de la Información" expuso su compromiso de trabajar activamente para lograr el multilingüismo en Internet, como parte de un proceso multilateral, transparente y democrático en el que intervengan los gobiernos y todas las partes interesadas, en sus respectivos papeles.

Desde la perspectiva antropológica, comenta Sandoval-Forero, "[...] el conocimiento, la comunicación las tecnologías de la información, las normas, el software y el hardware, son productos y expresiones culturales que corresponden a una condición histórica y a una realidad socio-política y económica de hegemonía del capital global". Y agrega que "[...] este contexto internacional, que también cuenta con las concreciones en el panorama nacional, dificulta el acceso y la apropiación de las Tecnologías de Información y Comunicación (TIC) por parte de los grupos étnicos y todos los demás sectores sociales denominados, vulnerables, sin impedir totalmente ciertas posibilidades de interactuar en esa dimensión tecnológica" (Sandoval, 2013: 241).

En las últimas décadas, un porcentaje de las comunidades indígenas no sólo del país, sino de todo el mundo, se han visto avasalladas por la cantidad de información generada y transmitida por los medios de comunicación y por la inserción de las tecnologías en sus actividades cotidianas en aspectos tan varios como el comercio, la salud, la economía, el transporte, la comunicación, su organización social y su cultura.

Esto se puede observar, por ejemplo, en el Estado de Oaxaca donde, como comenta Mayra Martínez "[...] el Instituto Nacional de Estadística y Geografía (INEGI), indica que sólo el 14.6\% de los hogares cuentan con Internet y esto obedece a la carencia de recur- 
sos económicos. Del mismo modo, de los 232 mil hogares que tienen computadoras personales, es decir, el 35.1\% comentaron que carecen de conexión a Internet; de éstos, dos de cada tres hogares (61.4\%), no cuentan con recursos económicos para acceder a internet y $15.1 \%$ dijeron que no les interesa disponer de dicha red" (Martínez, 2015).

A nivel nacional, destacan la Ciudad de México, Nuevo León, y Baja California, como las entidades donde de cada dos hogares uno cuenta con conexión a Internet; en contraste, Chiapas, Oaxaca y Guerrero, reportaron que únicamente dos de cada diez hogares cuentan con tal acceso.

Esta situación ha provocado que entre estas familias, haya una serie de diferencias que se perciben en cambios en su forma de actuar, de vestir, de trabajar, de ver la vida, de sentir su identidad, y también ha provocado actitudes relacionadas estrechamente con la preservación de su cultura.

\section{USUARIOS 2.0}

Los usuarios denominados 2.0 tienen una doble característica: son los individuos que tuvieron que aprender a adaptarse a las nuevas circunstancias tecnológicas e integrar éstas a sus trabajos cotidianos y a sus relaciones interpersonales. Y por otra parte, son aquellos que nacieron en la era digital y por consiguiente son usuarios expertos en el manejo de las TIC y a los cuales se les llama nativos digitales.

De acuerdo con Serrat-Brustenga y Sunyer-Lázaro, "[...] son también conocidos como generación Google, generación YouTube, generación red o generación digital, teniendo un comportamiento que los caracteriza y concretamente un comportamiento informacional diferente a las pasadas generaciones" $(2008,2)$.

Pero el Usuario 2.0 no es un conformista que busca cualquier tipo de información, sino alguien que pretende ser parte de la evolución de Internet y muestra interés por conocer, desarrollar y aprovechar las nuevas aplicaciones que presenta la Web 2.0 y que siguen desplegándose. 
Ortega Santamaría, indica que este tipo de usuario se afana en saber cómo "[...] aportar, difundir, compartir, colaborar y comunicar sus conocimientos, organizando sus sitios personales y profesionales en la red como puntos o espacios de sociabilidad, capaces de facilitar la creación y la gestión de múltiples redes personales y sociales" (2007).

\section{LA WEB 2.0}

La Web 2.0 es definida por Margaix como "[...] las aplicaciones que sacan partido a las ventajas intrínsecas de la web, ofreciendo un servicio que mejora cuanto más gente lo use, utilizando y remezclando los datos de múltiples recursos, incluyendo a los usuarios individuales, a la vez que ofrecen sus datos y servicios de tal forma que pueden ser reutilizados por otros, creando una arquitectura de participación en red, yendo más allá de la página de la Web 1.0 para ofrecer experiencias de usuario cada vez más ricas" (Fuentes, 2014:18).

O’ Reilly se refiere a la Web 2.0 como una segunda generación de la percepción basada en los servicios web como las redes sociales, sitios, wikis, herramientas de comunicación, y folksonomías que enfatizan la colaboración y el intercambio entre usuarios en línea (2005).

Por otra parte, algunos expertos bibliotecarios se refieren a la Web 2.0 como una web de lectura/escritura, donde los usuarios son consumidores y productores de líneas de contenido; un interactivo bidireccional de la web y un lugar donde la gente que cuenta con acceso a Internet puede crear y editar material.

De igual forma, Mariana Reyes menciona que "a partir del surgimiento de la Web 2.0, se implementa la tendencia de trabajar voluntaria y gratuitamente en la creación, aportación y edición de distintos contenidos. Para ello, influyen dos elementos que son: la inteligencia colectiva y la confianza radical. La confianza radical influye en que todos los usuarios que participan en algún sitio web, deben confiar en los contenidos que cada quien aporta. La 
inteligencia colectiva es la forma en que cada uno aporta sus conocimientos, tanto al desarrollo como al contenido de los sitios web" (Reyes, 2014: 100).

Los servicios que proporciona la Web 2.0 son muy variados: blogs, wikis, RSS (sindicación realmente simple), y opiniones añadidas por el usuario: mensajería instantánea, podcasts y vodcasts, folksonomías, nubes de marcado y etiquetas, marcadores sociales, sitios de redes sociales, trasmisión de audio y video, servicios de fotografía comunitaria o para compartir fotos y otros servicios para la comunidad y publicaciones.

\section{COMUNIDADES INDÍGENAS}

Las comunidades indígenas que realizan trabajo artesanal de campo, ganadero y de pesca, ya sea de manera independiente o como empresas familiares $\mathrm{u}$ organizadas en cooperativas, han aprendido a utilizar las TIC como medio de comunicación con proveedores de insumos para sus productos, y a hacer investigación de mercados tanto en México como en el extranjero para hacer la comercialización de los mismos, y elaborar índices de precios de las mercancías y costos de transporte, entre otras cosas.

También están las comunidades que laboran en el campo cultivando productos agrícolas y aquellos que se dedican a la producción de carnes, lácteos y otros derivados, y está el trabajo ganadero con diversos tipos de ganado o la producción de una amplia gama de animales y alimentos derivados de éstos.

La utilización de los servicios de la Web 2.0 por parte de algunas comunidades indígenas que han tenido el valor de conseguir las condiciones materiales, y adquirido las habilidades y capacidades necesarias para potenciar sus condiciones de vida y contribuir al desarrollo social y cultural de sus poblaciones, tratan siempre de abatir la pobreza y el analfabetismo, entre otros aspectos, que se ven reflejados en las personas y organizaciones que se mencionan a continuación como ejemplos claros de la capacidad comunitaria para hacer realidad sus metas: 
- Huellas Que Trascienden, A. C. www.huellasquetrascienden.org, organización cuyo objetivo es erradicar la pobreza en las comunidades indígenas de Chiapas, a través de la mujer. Creada en el año de 2013, esta página brinda asesora a las mujeres indígenas para aumentar su productividad y mejorar su economía, con el fin de lograr una mejor educación y alimentación para sus familias. Esta organización utiliza como medio de comunicación y difusión la Internet con una página Web 2.0, donde indica quiénes son, qué los diferencia y cómo trabajan. Tienen además un blog para dar a conocer las noticias que se publican sobre la organización, el trabajo que realizan, sus logros y también cuentan con RSS para compartir contenidos en la red de manera automática y actualizada.

- William Turner comenta la experiencia de Rodrigo Pérez Ramírez, un indígena zapoteco del estado de Oaxaca, ingeniero agrónomo graduado de la Universidad de Chapingo, Estado de México, quien investigó sobre las herramientas digitales disponibles en zapoteco, su lengua materna, y como no encontró resultados, decidió entonces aplicar los conocimientos que adquirió sobre software libre en la organización "Ingenieros sin Fronteras" en España, donde realizaban proyectos sustentables en poblaciones vulnerables, uno de los cuales implicaba al software libre. Los equipos de cómputo funcionaban con Ubuntu (un sistema operativo creado en Linux). "Aprendí las bondades del software libre para poder cambiarle el idioma a las aplicaciones", dice. Ahora que el 80\% del navegador Mozilla ya está traducido al zapoteco, Rodrigo recuerda sus comienzos en la traducción, cuando la Fundación Mozilla México se interesó en su idea y comenzaron a trabajar juntos para traducir línea por línea los casi 21, 000 caracteres que componen el código de esta aplicación.

Aunque el programa ya se puede descargar, el proyecto carece de apoyos para terminarlo. "Incluso organismos como el Instituto Nacional de Lenguas Indígenas ven estos proyectos como pequeños emprendimientos. Ellos se intere- 
san más por el lado político que el práctico", asegura Rodrigo (Turner, 2011).

- Desde 1974, el organismo internacional INCOMINDIOS se ha caracterizado por defender los derechos humanos de los indígenas, sobre todo del área Norte, Centro y Sudamérica; con apoyo de la Agencia Suiza para el Desarrollo y la Cooperación (COSUDE), desde 2003 ofrece una plataforma para desarrollar una posición global de los pueblos indígenas para la Cumbre Mundial de la Sociedad de la Información. Es importante mencionar que este organismo tiene el estatus de un órgano consultivo de la Organización de Naciones Unidas (ONU).

- Eduardo Sandoval describe en forma breve y clara como "[...] los pueblos y comunidades indígenas vienen construyendo procesos comunicativos comunitarios alternativos, para visibilizar y fortalecer sus proyectos identitarios; es decir, de política propia. Estos colectivos indígenas se han apropiado de las TIC y las han articulado a sus formas tradicionales de comunicación para interactuar hacia el interior de sus comunidades, y también para dar a conocer e interrelacionarse con los no indígenas; es decir, para el ejercicio de la comunicación intercultural.

El sentido de la apropiación de las TIC digitales y virtuales por parte de las comunidades y pueblos indígenas, cumple con principios no sólo comunicacionales en grupos donde la tradición oral ha sido determinante para la continuidad social y cultural, sino también para informar, reflexionar, discutir, denunciar, acordar y actuar.

Este accionar que desde la perspectiva antropológica se califica de resistencia cultural, ha sido ilustrado de manera elocuente por el movimiento indígena zapatista en México desde sus orígenes hasta sus actuales quehaceres cotidianos con el uso de Internet, emisoras rebeldes, páginas web, chats, videograbaciones y blogs, todo ello en función de la construcción autonómica como pueblos diferenciados histórica, social y culturalmente en México" (Sandoval-Forero, 2013: 242). 
- El caso de los Triquis es emblemático en la medida en que esta comunidad, situada al oeste del estado de Oaxaca, se asienta en una región montañosa de difícil acceso. Con la creación del portal (www.triquis.org) y el sitio web (www. triquicopala.com), por mencionar sólo dos espacios de la red, el acercamiento de los internautas a las tradiciones, estilo de vida, las noticias e incluso los videos y actividades culturales relacionadas con las tradiciones de esta comunidad, están a sólo unos clicks de distancia.

Asimismo, estos sitios ofrecen un punto de encuentro para miembros de las comunidades que están en otros lugares de la República Mexicana y el extranjero, lo que permite la continuación de un contacto con sus raíces, el habla y eventos relacionados con la comunidad de la que forman parte, aun estando lejos de casa.

Iniciativas como los sitios web antes mencionados ofrecen una presencia en la red que genera puntos de re-encuentro y ámbitos de difusión para arraigar la identidad y las tradiciones, al mismo tiempo que funcionan como elemento concentrador de conocimiento y difusión de noticias para una comunidad que encuentra posibilidades de contacto y comunicación con los suyos en un lazo que aunque virtual, no deja de lado su realidad.

Otro factor importante es el relativo a los medios de comunicación que han abierto posibilidades para las generaciones jóvenes de las comunidades indígenas para conocer a través de las TIC el mundo que los rodea y que se encuentra fuera de las fronteras de sus localidades de origen. También, les dan la oportunidad de apropiarse de otras costumbres y actitudes, aunque muchas veces en detrimento de la preservación de su propia cultura.

Hablando de cultura, no se puede dejar pasar la oportunidad que ofrecen las TIC para ayudar a las comunidades a preservar y difundir esa cultura a través de dichos medios. Ejemplo claro de eso son las comunidades que por medio de las redes sociales han desarrollado estrechos lazos con grupos de su comunidad asentados 
en otras localidades, pero que mantienen sus costumbres y tradiciones, su folklore y su cultura en general, además de difundirla y promoverla.

Por otra parte, están las comunidades que tienen un alto índice de migración, las que gracias a los recursos económicos que han logrado obtener debido a los empleos conseguidos fuera de sus lugares de origen, y con la educación general y la capacitación en el uso de tecnologías, han podido crear redes sociales entre los pueblos originarios y las comunidades formadas, tanto en otras localidades del país como en el extranjero, y han conseguido establecer comunidades alrededor de las zonas de trabajo.

En estas comunidades, normalmente el factor que ha incidido para que puedan hacer uso de tecnologías y medios de comunicación radica en que la gente se haya ido de sus lugares de origen. Efectivamente, emigran a otros lugares y no sólo a nivel nacional sino más allá de las fronteras; y al hacer esto siguen teniendo comunicación con sus comunidades, pero ya a través del desarrollo de las TIC que ellos contribuyeron a generar con el envío de recursos de diversa índole: dinero en efectivo y equipo de cómputo, electrónico y digital.

Estas personas utilizan tanto la radio como la televisión y la telefonía de forma constante, y tienen unidades de información virtuales con Internet y otros medios electrónicos e infraestructura que les permite acceder a la información, y además cuentan con recursos económicos. También utilizan Internet inalámbrico, la Web 2.0, las redes sociales y otras aplicaciones y recursos tecnológicos. Entre éstas, aquí en México por ejemplo, figuran algunas de las comunidades indígenas de Zacatecas, Guerrero, Michoacán y Oaxaca. Aquellas comunidades que no son usuarias de tecnologías ni medios de comunicación, tienen grandes problemas de desarrollo en todos los aspectos debido a muchos factores, entre ellos un acercamiento muy esporádico a otros grupos sociales, por lo que su acceso a otro tipo de información es escaso o no existe. Es decir, no es que ellos lo quieran así, la información que normalmente utilizan es transmitida de manera oral, o es la que expiden sus autoridades o consejos de ancianos, familiares o amigos. Y su cono- 
cimiento del mundo no se amplía al carecer de infraestructura y no poseer una capacidad económica. Esto demuestra la gran desigualdad que existe entre la información que utilizan los diversos grupos étnicos.

\section{LA IMPONDERABLE BRECHA DIGITAL}

Se considera que para mejorar y homologar las condiciones de apropiación, uso y democratización es pertinente la incorporación de tecnologías informativas y de comunicación entre las comunidades, para lo cual hay que :

- Atenuar y reducir la brecha digital entre estas comunidades, pues como se acaba de mencionar, existe una gran desigualdad en el acceso y uso de estas tecnologías entre ellas. Algunos de los problemas detectados más prioritarios son: "la carencia de instalación de infraestructura eléctrica que asegure la conectividad en zonas marginadas; difíciles condiciones geográficas y climáticas; altos costos de transportación de equipos e insumos, así como la instalación de los sistemas y su mantenimiento; falta de condiciones de arraigo para el personal técnico y profesional; falta de conocimiento y motivación para manejar nuevas tecnologías por sus altos costos y el rechazo al manejo de estas tecnologías por carencia de significado en sus proyectos y expectativas" (Casillas, 2012: 28).

- Considerar esta área como prioritaria para hacer estudios e investigaciones que conlleven a detectar y especificar el tamaño de la brecha, los factores que han incidido en su surgimiento y posteriormente proyectar el abatimiento de esta brecha.

- Generar políticas públicas en el área de las TIC. En relación con las políticas públicas de información y comunicación, es necesario formular propuestas viables para que el Estado las incorpore en su Plan Nacional de Desarrollo, con el 
fin de que la desigualdad existente entre los grupos vulnerables, incluidas las comunidades indígenas, no siga persistiendo. El gobierno debe convencerse de que las comunidades indígenas tienen condiciones para utilizar las TIC en su provecho, y que de lograr esto serían comunidades que ayudarían al desarrollo del país viviendo en paz y armonía, y preservando las raíces culturales e identitarias de la nación.

- Homologar la distribución de recursos tecnológicos para tener una buena recuperación y acceso a la información. En México esto sería posible a través de programas como "Libre Internet para todos".

- Implementar una red de datos que, como la red eléctrica que existe en el país, logre conectar a todas las comunidades, aun aquellas que se encuentran en los confines del territorio nacional. Esta situación ha sido imprecisa y ahora se está considerando la posibilidad de utilizar la red eléctrica que existe a nivel nacional, para permitir la recepción y el envío de datos, lo que abatiría los costos de diseño e implementación de una nueva red, además de que se podrían utilizar los recursos económicos ahorrados para adquirir y entregar estos recursos tecnológicos a las comunidades que así lo requirieran.

- Ampliar la utilización de los medios de comunicación. Algunas comunidades utilizan todos los medios de la Web 2.0 para comunicarse con sus coterráneos donde sea. Hay también comunidades que únicamente utilizan la radio para obtener información hacia el interior, pero el flujo de esta información es endogámico y es sólo para las familias, parientes y amigos de esa misma localidad. De lograr usar las tecnologías de información y los medios de comunicación de manera más expedita y con mejores recursos, tales comunidades obtendrían información actualizada, abundante e interesante; además de que ampliarían su universo y se comunicarían con sus congéneres y otras personas ubicadas fuera de la comunidad. 
- Eliminar las diferencias de infraestructura bibliotecaria y de información entre estas comunidades. Al integrar instituciones bibliotecarias en cada una de las poblaciones indígenas con medios de comunicación, que garanticen un servicio y un flujo de intercomunicación constante, ya sea ésta verbal, visual o escrita, se empezaría a construir un sistema de información que apoyaría a las comunidades a descubrir otras formas de organización, otros métodos de trabajo y mejores condiciones para incorporarse a otros niveles de vida, y a establecer conductas que les permitieran adecuar su interacción con las sociedades que los rodean, entre otros aspectos importantes para su desarrollo.

- Uniformar servicios de información para el conjunto de estas comunidades. Como ya se comentó, en Zacatecas, Oaxaca, Michoacán y otros lugares como Nayarit y Colima utilizan ya una serie de servicios de información de redes e Internet que no solamente están dirigidos a la mayor parte de los jóvenes y niños, sino también a los adultos y personas de todas las edades que tienen la necesidad de emigrar. Algunas de estas necesidades de información son las siguientes: ¿qué solicita el Consulado para apoyar la tramitación de trabajos temporales en otro país?, ¿qué se requiere, dónde y cómo se tramita un pasaporte?, ¿cómo se pueden enviar recursos económicos sin riesgo a los familiares? Como se puede observar, la información que en un momento dado requieren los emigrantes es mucha, por lo que se deben considerar servicios muy precisos. ¿Por qué no ofrecerles a las personas adultas de esas comunidades, servicios electrónicos parecidos o iguales a los que ofrece el propio gobierno para pagar impuestos, el predial, la tenencia de automóviles, el agua, y la electricidad?

- Establecer planes de capacitación y formación en el área a individuos nativos. Incorporar a los miembros de la propia comunidad en el trabajo y las actividades que comprenden los servicios con tecnologías de información y comunicación es un punto crucial en la atención hacia las poblaciones indígenas. 
Por ello, es de suma importancia generar un programa de capacitación y/o formación de técnicos y profesionales para individuos que colaboren dentro de sus comunidades con trabajo en las unidades de información que operen con recursos impresos, electrónicos y digitales.

- Hacer estudios sobre las necesidades de información de las comunidades indígenas. En realidad, casi siempre la conformación de unidades de información ha surgido sin tener conocimiento de los individuos a quienes se les proporcionarán servicios de información y la información misma; es decir, en muchas ocasiones no se sabe a ciencia cierta para quién se están construyendo edificios, planeando servicios, adquiriendo y organizando documentos e incorporando tecnologías de información y comunicación. En este sentido, es de vital importancia que se elaboren estudios de necesidades de información sobre las comunidades indígenas antes de planear, construir e implementar un recinto bibliotecológico y de información. De este modo, luego de conocer sus requerimientos informativos podría visualizarse una entidad bibliotecológica e informativa que verdaderamente los apoyara con servicios y productos de calidad en la búsqueda de respuestas veraces y oportunas. Debemos recordar que aquella biblioteca que no conoce a sus usuarios y sus necesidades de información, no tiene razón de ser.

- Impulsar la creación de sistemas de información adecuados a las necesidades informativas de las comunidades indígenas. Después de conocer qué es lo que requieren en cuanto a información, se podrán establecer una serie de iniciativas y proyectos que facilitarán la construcción o adecuación de edificios bibliotecarios y de información con una infraestructura tecnológica y digital que contemple una serie de servicios de calidad, necesarios para apoyar el desarrollo social, económico y cultural de estas comunidades.

- Además, como indica María de Lourdes Casillas es necesario "[...] diseñar una estrategia de alfabetización digital para el manejo de estas tecnologías que considere: a) la cul- 
tura del entorno, b) el dominio de los procesos de comunicación en lenguas autóctonas, y la posibilidad de que c) los contenidos se fundamenten en un diagnóstico sobre los proyectos actuales de desarrollo. Los intereses y las expectativas de la población, así como en las potencialidades de desarrollo de la comunidad, a futuro" (Casillas, 2012: 29).

\section{AGENDA DE INVESTIGACIÓN}

Es necesario establecer una serie de estudios que permitan vislumbrar una sociedad más igualitaria, equitativa y justa en relación con las comunidades indígenas, lo que incidiría, en pocas palabras, en la reconstrucción del tejido social. Partiendo de estas consideraciones anteriores, se presentan algunas propuestas con las que se puede configurar una agenda que permita generar proyectos de investigación que acerquen los servicios de información de la Web 2.0 a las comunidades indígenas:

- Promover el uso de sistemas de información. La elaboración de proyectos de investigación encaminados a planear, organizar y distribuir medios electrónicos y digitales que permitan el acceso y uso de los sistemas de información a través de la Web 2.0, para que éstos se conviertan su vez en medios de información comunes para la población indígena.

- Realizar programas encaminados a la edición de material literario. La producción de documentos académicos y científicos en lenguas indígenas sobre diversas disciplinas, en acceso abierto y en texto completo, donde por ejemplo, se pueda mencionar la cosmogonía de los pueblos originarios, la medicina tradicional y los conocimientos que se derivan de la herbolaria y la botánica. Es importante mencionar la trascendencia y riqueza de los resultados que tendrían estos proyectos si se llevaran a cabo haciendo interactuar a los propios dueños del conocimiento; es decir los llamados cha- 
manes, curanderos, yerberos y chamanes sabios, entre otros, quienes con su vasto conocimiento, aportarían información importante recolectada por generaciones de individuos y comunicada por tradición oral.

- Desarrollar programas interactivos en la web 2.0 relativos al impulso del hábito de la lectura en lenguas nativas y en español. Estos programas se pueden integrar a través de las bibliotecas públicas con aquellos mencionados en el párrafo anterior y con los programas de alfabetización de organismos gubernamentales y no gubernamentales, con el fin de elevar las estadísticas de alfabetización y de lectura a nivel nacional.

El factor humano siempre es imprescindible en el establecimiento de proyectos de largo alcance, sobre todo cuando se integran diversas disciplinas y profesiones. La realidad actual demanda que se trabaje interdisciplinariamente con mayor frecuencia, por lo cual convocamos a los bibliotecólogos, sociólogos, etnólogos, arqueólogos, comunicólogos, historiadores, geógrafos, ingenieros, médicos, gastrónomos, veterinarios, químicos, físicos, economistas, biólogos, botánicos y pedagogos que se encuentren colaborando en los diversos programas de utilización de los servicios de la Web 2.0, a que aporten su experiencia y conocimientos para lograr los objetivos planteados.

Por último, vale la pena preguntar ¿cuáles son los retos para confrontar la desigualdad en el uso de las TIC y concretar qué programas de formación en el uso de la Web 2.0 son los más pertinentes para las comunidades indígenas? A manera de respuesta se puede mencionar la conformación de grupos inter, multi y transdisciplinarios, que junto con organismos gubernamentales y no gubernamentales involucrados con las comunidades indígenas, se comprometan a consolidar redes académicas nacionales e internacionales y a apoyar con recursos de todo tipo, la puesta en marcha de las propuestas resultantes de estos programas. 


\section{CONCLUSIONES}

Estudiar las dificultades que presenta la interacción entre los individuos indígenas e Internet puede parecer irrelevante para algunos; sin embargo, este tipo de investigaciones nos permiten conocer y analizar lo siguiente:

- Las causas por las cuales sólo un porcentaje muy bajo de las comunidades indígenas se encuentra en posibilidades de utilizar las TIC y de ser consideradas usuarias 2.0.

- Las consecuencias positivas o negativas para las comunidades indígenas de contar o no con los recursos tecnológicos necesarios para utilizar los servicios de la Web 2.0.

- La viabilidad de planear estrategias de desarrollo de servicios bibliotecarios y de información, incorporando las TIC y los servicios de la Web 2.0.

- Las causas que inciden en el comportamiento informativo de los miembros de una comunidad indígena 2.0.

- Si al manejar las TIC se multiplican las fuentes y herramientas de consulta que pueden utilizar los usuarios indígenas 2.0.

- Si satisfacer las necesidades informativas implica mayor preparación y conocimiento para las comunidades 2.0 y por lo tanto un cambio en su propia identidad.

Con el fin de darle solidez a los planteamientos descritos a lo largo de este trabajo, se consideró pertinente presentar algunas de las conclusiones que emitió Sami Ayriwa en su tesis de Maestría: "La red de internet y los pueblos indígenas de América latina: Experiencias y perspectivas":

- "La presencia indígena en Internet es limitada en comparación con su presencia en la radio por ejemplo. Pero con esos mínimos espacios, los pueblos indígenas han documentado la vivencia de sus pueblos y la han puesto a circular en la red. 
- La presencia indígena en la red sobresale no sólo por la cantidad sino también por la variedad de procedimientos en las construcciones de las páginas, en las que se destaca el uso de los diseños indígenas y la combinación de colores. Si bien el control ejecutivo y técnico, de la mayoría de ellas se encuentran fuera de los pueblos indígenas, la información que contienen estas páginas web se hace con la participación, discusión y decisión de los indígenas acerca de lo que se debe circular.

- Ya se han puesto en práctica experiencias muy alentadoras, como el uso de la red de Internet para alfabetización en Brasil; el envío de mensajes en los pueblos iletrados de India; la creación de una red telemática indígena con el apoyo de la ONU; comercio electrónico indígena; intercambio de experiencias con otros pueblos indígenas y no indígenas, y sobre todo, la oportunidad de hablar por sí mismos, para sí mismos y también para la sociedad en general" (Ayriwa, 2000).

\section{BIBLIOGRAFÍA}

Ayriwa Pilco, S. (2000), La red de internet y los pueblos indígenas de América Latina: experiencias y perspectivas. Quito, Ecuador Tesis. Disponible en: <www.eurosur.org/TIPI/sami.htm >.

Becerra Cortés, Y. E. (2012), "Estudiantes indígenas y los usos y apropiación de las tecnologías de información y comunicación". En Paakat. Revista de Tecnología y Sociedad, año 2, núm. 3, septiembre-diciembre.

Casillas Muñoz, M. L. (2012), "Retos de la expansión de las tecnologías de la información y la comunicación en las comunidades indígenas de México”. En Etic@ net: Revista Científica Electrónica de Educación y Comunicación en la Sociedad del Conocimiento, año XII, núm. 12, vol. 1, enero-junio, pp. 16-37. 
"Comunidades indígenas generan espacios en internet" Disponible en: <http://suenamexico.com/verde-y-social/ comunidades-indigenas-generan-espacios-en-internet/>.

Doueihi, M. (2010), La gran conversión digital. Buenos Aires, México: Fondo de Cultura Económica.

Fuentes Gatica, L. A. (2014), Análisis de la búsqueda de información académica utilizando la web 2.0 por los alumnos de la Facultad de Ciencias de la UNAM. México.

Incomindios. International Committee for the Indigenous Peoples of the Americas. Disponible en: <http://incomin dios.ch/en/>.

Martínez, M. (2015), “Tener internet es todavía un lujo en Oaxaca". En NNS Oaxaca: Información minuto a minuto. Disponible en: <http://www.nssoaxaca.com/estado/31-general/ 121614-tener-internet-todavia-es-un-lujo-en-oaxaca-solo-146 -de-hogares-cuenta-con-conexion>.

O’́Reilly, T. (2005), ¿Qué es la web 2.0.? Disponible en: $<$ https://urra.files.wordpress.com/2007/08/que-es-web20-por-tim-oreilly.doc $>$.

Ortega Santamaría, S. (2007), "Evolución del perfil del usuario: usuarios 2.0". En NSU no solo usabilidad: revista sobre personas, diseño y tecnología. 28 de mayo. Disponible en: <http://www.nosolousabilidad.com/arti culos/usuario20.htm>.

Peltier-Davis, Ch. (2009), "Web 2.0, Library 2.0 User 2.0, Librarian 2.0: Innovative Services for Sustainable Libraries". En Information today, Inc. vol. 29, núm. 10, noviembre/diciembre, pp. 16-21. Disponible en: <www. infotoday.com/climag/nov09/index.shtml>.

Reyes Martínez, M. E. (2014), Cibercultura en la Biblioteca 2.0: nuevas implicaciones para la bibliotecología. Tesis. México. 
Sandoval-Forero, E. (2013), "Los indígenas en el ciberespacio". En Agricultura, Sociedad y Desarrollo, vol. 10, núm. 2, abril-junio, pp. 235-256.

(2012), "Las comunidades indígenas y la sociedad de la información. En II Encuentro del libro intercultural y en lenguas indígenas, XXIV Feria del Libro de Antropología e Historia, 5 octubre .

Serrat-Brustenga M. y Silvia Sunyer-Lázaro. (2008), "El Centro de recursos para el aprendizaje y la investigación (CRAI) en permanente transformación: servicios y recursos para el nuevo Usuario 2.0". En X Jornadas de Gestión de la Información, Madrid. España, 20-21 noviembre. Disponible en: <http://eprints.rclis.org/12559/>.

Turner M, W. (2011), "La filosofía del software libre se adentra en los pueblos indígenas". En CNN México. Disponible en: $<$ http://mexico.cnn.com/tecnologia/2011/08/15/la-filoso fia-del-software-libre-se-adentra-en-los-pueblos-indige nas>. 


\title{
Relación del usuario 2.0 \\ con las bibliotecas universitarias
}

\author{
LUISA ORERA ORERA \\ Universidad de Zaragoza
}

\section{LOS USUARIOS DE LA BIBLIOTECA UNIVERSITARIA}

$\tau$ a biblioteca universitaria es un sistema de información que tiene como principal misión proporcionarle a la comunidad universitaria todos aquellos servicios, documentos y recursos informativos, propios o ajenos, que son necesarios para que pueda desarrollar con eficacia sus funciones docentes, de aprendizaje y de investigación.

Partiendo de esta definición, los principales usuarios de la biblioteca universitaria pertenecen a dos colectivos: estudiantes y personal docente e investigador, en coherencia con las dos funciones clave que desempeñan las universidades, docencia e investigación, a cuyo apoyo debe ir dirigido el trabajo de la biblioteca universitaria.

\section{Estudiantes}

A pesar de tratarse de un colectivo con un denominador común el cual es cursar estudios universitarios, es, a su vez, un colectivo he- 
terogéneo con base en varios criterios de los que destacamos dos: el nivel de los estudios que se cursan y la edad.

De acuerdo con la organización que establece el Espacio Europeo de Educación Superior (EEES), la enseñanza universitaria se organiza en: grado, máster y doctorado. Actualmente todavía se están cerrando niveles propios de la etapa anterior a su implantación, es decir, titulaciones de primero y segundo ciclo.

Según los estudios estadísticos del Ministerio, ${ }^{1}$ en el curso 20112012, el número de estudiantes matriculados en las universidades españolas en grado y máster se situó en 1582714 , lo que supone una tasa neta de escolarización universitaria entre 18 y 24 años, del $27.9 \%$.

Desglosando dichas cifras, el número de estudiantes de grado de primer y segundo ciclo ascendió a 1469653 estudiantes. En el mismo curso, se impartieron 2668 másteres universitarios, con un total de 113061 estudiantes matriculados. A esto hay que añadir que en el año 2011 se leyeron 9487 tesis doctorales.

Como ya hemos señalado, otro de los elementos diferenciadores del colectivo es su edad. Por lo que se refiere a los estudiantes de 1 er y 2 ciclo y grado, un 40.6\% tiene entre los 18 y los 21 años; un $27.7 \%$ tiene entre 22 y 25 años; un $13.2 \%$, entre 26 y 30 años y un $18.5 \%$ son mayores de 30 años.

En el caso de los másteres oficiales, el 24.3\% es menor de 25 años, un $40.7 \%$ tiene entre 25 y 30 años; un $24.7 \%$, entre 31 y 40 años y un 10.2\% tiene más de 40 años.

En el caso de las personas que han presentado la tesis, el 19.9\% tiene entre 24 y 29 años; el $36.5 \%$ entre 30 y 34\%; el $16.4 \%$ de 35 a 39 años; el 9.1\% de 40 a 44 años; el 7.8\% de 45 a 49 años; el 6.2\% de 50 a 55 años y el $4.5 \%$ tiene más de 55 .

1 Datos y cifras del sistema universitario español. Curso 2012-2013 [en línea]. Madrid: Ministerio de Educación, Cultura y Deporte, 2012. 
Personal docente e investigador (PDI)

En el curso $2010-2011,{ }^{2}$ el PDI de las universidades españolas ascendía a 115218 miembros. Como en el caso anterior, se trata de un colectivo con un denominador común, el ejercicio de la docencia y/o la investigación, pero que presenta diferencias. Existe personal funcionario (catedráticos de universidad, titulares de universidad, catedráticos de escuela universitaria, titulares de escuela universitaria y otro personal funcionario), personal emérito y personal contratado (de centros propios y adscritos). De este colectivo, el $65.4 \%$ es doctor.

En cuanto a la edad, hay que señalar que el $12.2 \%$ de la plantilla es mayor de 60 años.

\section{USUARIOS 2.0}

Referirnos a los Usuarios 2.0 en la biblioteca universitaria, requiere que tratemos de definir, aunque sea brevemente, qué es la Biblioteca 2.0.

El término Biblioteca 2.0 fue utilizado por primera vez en 2005 por Michael Casey en su blog LibraryCrunch. Desde entonces, los ejemplos se han ido multiplicando. De ellos recogemos algunos a continuación:

1. Paul Miller ${ }^{3}$ dio una sencilla definición: "Web $2.0+$ bibliote$\mathrm{ca}=$ Biblioteca 2.0".

2. Serrano Cobos $^{4}$ resalta como notas características de la Biblioteca 2.0 las siguientes:

- Permite y fomenta la participación del usuario/cliente no sólo en el disfrute de la misma, sino en su gestión.

2 Ibid.

3 P. Miller, "Web 2.0: Building a New Library".

4 J. Serrano Cobos, Web 2.0 en las bibliotecas: el concepto Library 2.0. 
- Es divertida, trabaja para el usuario, habla de compartir y no sólo de consultar o pedir un préstamo, de crear redes de usuarios, de comunicar y facilitar la comunicación entre usuarios, bibliotecarios y entre los propios usuarios.

- Socializa la recuperación y arquitectura de la información en un sistema escalable, que permite descentralizar la clasificación de los contenidos.

3. Margaix ${ }^{5}$ la define como: "[...] la aplicación de las tecnologías y la filosofía de la Web 2.0 a las colecciones y los servicios bibliotecarios, tanto en un entorno virtual como real".

A través de la exposición anterior se ve que la nota más característica de la Biblioteca 2.0 es el papel del usuario. El Usuario 2.0 se convierte en un agente activo en la elaboración y gestión de contenidos. Margaix Arnal ${ }^{6}$ fundamenta esta nueva visión del usuario en dos principios filosóficos:

1. La confianza radical en el usuario, lo que implica fiarse plenamente de ellos en cuanto al uso de los servicios, la información aportada, etc.

2. El aprovechamiento de la inteligencia colectiva, recogiendo el conocimiento aportado por los usuarios para que otros puedan reutilizarlo y aprovecharlo.

En resumen, podríamos decir que en la nueva relación establecida entre el usuario y la biblioteca se han producido dos grandes cambios. La comunicación entre la biblioteca y el usuario es ahora bidireccional, y el usuario se ha convertido en un creador de contenidos.

5 D. Margaix Arnal, "Conceptos de Web 2.0 y Biblioteca 2.0: origen, definiciones y retos para las bibliotecas actuales". p. 102.

$6 \quad$ Ibid., pp. 100-101. 


\section{APLICACIONES 2.0 EN LAS BIBLIOTECAS UNIVERSITARIAS}

Esta nueva relación se materializa en lo que podemos denominar aplicaciones o Herramientas 2.0, de la web social o, como se las conoce más recientemente, social media.

Transcurrida la primera etapa de euforia en que se descubre la biblioteca 2.0 en España, pensamos que el desarrollo de la Biblioteca 2.0 ha entrado en una etapa de serena reflexión, durante la cual las bibliotecas universitarias van desarrollando este tipo de aplicaciones, integrándose poco a poco en el trabajo cotidiano. Su implantación en las bibliotecas universitarias españolas se contempla de forma generalizada en el III Plan estratégico de REBIUN 2020 , cuya Línea 3 se dirige a "Potenciar el desarrollo y uso de la

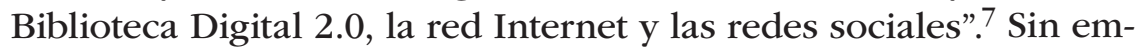
bargo, con las cautelas que impone el hecho de estar hablando de un entorno que cambia a gran velocidad, algunos estudios revelan que, hablando de forma general, la implantación de estas herramientas en las bibliotecas universitarias españolas es todavía escasa. Herrera Morillas ${ }^{8}$ ha constatado que, aunque el $90.4 \%$ de las bibliotecas universitarias españolas utilizan alguna herramienta de la web social, el $17.4 \%$ sólo utiliza un tipo de recurso y el $25.3 \%$, sólo 2 .

Por otra parte, no basta con implantar herramientas, sino que debe hacerse de forma planificada, elaborando políticas donde se establezcan, al menos, las herramientas concretas que se quieren implantar y los objetivos que se quieren conseguir. Un proceso de implantación de calidad requiere también la elaboración de guías de uso sobre los diferentes recursos, ${ }^{9}$ su actualización, la evaluación del uso de las distintas herramientas y el diseño de planes de

7 REBIUN. III Plan estratégico de REBIUN 2020.

8 J. L. Herrera Morillas y Castillo Díaz, A. "Bibliotecas universitarias 2.0. El caso de España”, pp. 175-200 .

9 Algunas bibliotecas universitarias españolas han comenzado a elaborar guías de uso de la web social. Como ejemplo puede consultarse: Biblioteca Universidad de Sevilla, Guía de usos y estilo de la web social en la BUS. 
formación de usuarios adaptados a sus diversas necesidades. En relación con esto último hay que tener en cuenta que, aunque se trata de herramientas de uso sencillo, no todos los usuarios de las bibliotecas universitarios son nativos digitales.

En España, existe una abundante literatura dirigida al estudio de las Herramientas 2.0 y su aplicación en las bibliotecas en gene$\mathrm{ral}^{10} \mathrm{y}$ en las universitarias en general. ${ }^{11}$ De igual manera, intentos de clasificación de las mismas, tarea muy difícil como ha puesto de manifiesto Merlo Vega:

"Las tecnologías, recursos, servicios, aplicaciones informáticas, proveedores [...] que se pueden etiquetar como web social son diversos. Las tecnologías de la participación son múltiples. No es fácil sistematizar este tipo de servicios, sin arriesgarse a ofrecer una clasificación que quede inmediatamente desactualizada o a equivocarse al incluir/excluir servicios participativos dentro de la posible ordenación que se haga de los procedimientos existentes". ${ }^{12}$

El mismo autor ${ }^{13}$ agrupa y define estos servicios en diez apartados: weblogs (sitios web que permiten la constante introducción de comentarios y el archivo de los mismos); wikis (espacios en los que diversos autores pueden crear contenidos desde su navegador); sindicación de contenidos (posibilidad de que los contenidos de

10 Como ejemplos pueden consultarse: N. González Fernández-Villavicencio. Bibliotecas 2.0 en España: el camino recorrido. Boletín de la Asociación Andaluza de Bibliotecarios, pp. 29-46.

D. Margaix Arnal, Informe APEI sobre social.

11 Citamos a continuación dos de estos trabajos: J. L. Herrera Morillas, Castillo Díaz, A. "Bibliotecas universitarias 2.0. El caso de España”, op. cit. Un estudio que cuantifica el uso de herramientas 2.0 en las bibliotecas universitarias.

REBIUN. Ciencia 2.0: aplicaciones de la web social a la investigación [en línea], 2010. < http://eprints.rclis.org/3867/1/Ciencia20_rebiun.pdf>. Fecha de consulta: 6 de marzo de 2014. Se trata de un estudio que tiene por objeto sistematizar las aplicaciones de la web social que pueden servir de apoyo a los investigadores y, por lo tanto, de interés para las bibliotecas que apoyan la labor de investigación, como las universitarias.

12 J. A. Merlo Vega, Las tecnologías de la participación en las bibliotecas, p. 3.

13 Ibid., pp. 3-4. 
algunas webs se redifundan a través de lectores específicos, navegadores o servicios externos); etiquetado (sistemas de descripción de contenidos por parte de los usuarios de un servicio, mediante la aplicación de términos del lenguaje natural); recomendaciones (servicios que permiten a los usuarios valorar, mediante comentarios, la calidad de una información, el interés de una noticia o el valor de un producto); compartir archivos (servidores web donde los usuarios pueden depositar archivos — audio, video, imágenes, etc.- para ser consultados de forma abierta); geoaplicaciones (herramientas que trabajan con información geográfica, permitiendo la integración y combinación con diferentes recursos web); utilidades (son aplicaciones de carácter ofimático con las que se trabaja en línea, por lo que permiten compartir archivos); redes sociales (entornos virtuales que permiten relacionarse a los usuarios e intercambiar información y archivos); búsquedas (sitios web y aplicaciones en los que la recuperación de información se hace teniendo en cuenta la opinión y comportamiento de los usuarios). Las aplicaciones más extendidas en las bibliotecas universitarias españolas son las siguientes: ${ }^{14}$

1. OPAC $2.0(75.4 \%)$

2. Redes sociales (59.64\%)

3. Blogs (57.89\%)

4. $\operatorname{RSS}(50.87 \%)$

5. Compartir recursos multimedia (22.80\%)

6. Mensajería instantánea (19.29\%)

A ellas vamos a referirnos a continuación.

14 J. L. Herrera Morillas y Castillo Díaz, A., "Bibliotecas universitarias 2.0. E1 caso de España”, op. cit. p. 189. 


\section{OPAC 2.0}

El OPAC 2.0 es el resultado de aplicar las tecnologías y actitudes de la Web 2.0 al catálogo de la biblioteca. Margaix Arnal ${ }^{15}$ ha puesto de manifiesto la aplicación de la inteligencia colectiva como factor determinante para el desarrollo del OPAC $2.0 \mathrm{u}$ OPAC social, señalando los tipos de información que pueden enriquecer el catálogo:

1. Información ofrecida por los usuarios. Se trataría de información aportada de forma consciente y deliberada: reseñas de los documentos, puntuaciones (rating), etiquetas (tagging), etcétera.

2. Información derivada del uso del catálogo y de otros servicios por los usuarios de la biblioteca: préstamo de ejemplares, las veces que un ejemplar ha sido guardado como favorito, etc.

3. Bibliografías recomendadas en las diferentes asignaturas que integran los planes de estudios de las universidades, imprescindibles para detectar las necesidades de los estudiantes. Se trataría de aprovechar esa información para que esté disponible cuando se realiza una búsqueda o cuando se visualiza un registro.

4. Información externa producida fuera de la institución, pero que puede incorporarse al catálogo: reseñas de libros publicadas en revistas especializadas, el índice de impacto de una revista, etc.

15 D. Margaix Arnal, Informe APEI sobre social [en línea]. Gijón: Asociación Profesional de Especialistas en Información, 2008, <http://eprints.rclis.org/ 12506/1/informeapeiwebsocial.pdf $>$. [Fecha de consulta: 6 de marzo de 2014]. 
Respecto a la implantación en las bibliotecas universitarias españolas, Herrera Morillas ${ }^{16}$ ha señalado que son muy pocas las bibliotecas que han cambiado el OPAC tradicional por el 2.0, limitándose en muchos casos a añadir información al OPAC tradicional. Los cambios han consistido fundamentalmente en la incorporación de herramientas para buscar en la red, anadiéndoles a los registros elementos tales como la imagen de la cubierta del libro, enlaces a recursos informativos, la creación de listas de libros, la inclusión de etiquetas, comentarios, etc.

\section{Redes sociales}

Las redes sociales han existido siempre y pueden definirse como un grupo de personas relacionadas entre sí. Cuando hablamos de redes sociales en el contexto de la Web 2.0, nos referimos a sitios web con características especiales para crear redes sociales. Es el caso de Facebook, Tuenti, Twitter, LinkedIn, etc.

Arroyo las ha definido como:

Aquellos servicios web que, en el marco de la llamada web social o Web 2.0, permiten a los individuos construir un perfil público o semi-público dentro de una plataforma en línea a través de la cual es posible crear y gestionar nuestra red de contactos, comunicarse de diversos modos con otras personas con perfiles en esa misma plataforma y agregar contenidos multimedia. ${ }^{17}$

16 El estudio de J. L. Herrera Morillas y Castillo Díaz, A. "Bibliotecas universitarias 2.0. El caso de España”, op. cit., pp. 189-190, señala que de las 43 bibliotecas que tienen OPAC 2.0, realmente sólo 7 han cambiado al OPAC 2.0 (producto Encore, de Innovative Interfaces), ya que el resto, 36 bibliotecas, se han limitado a añadir información o elementos propios de OPAC 2.0 al catálogo tradicional.

17 N. Arroyo Vázquez, "Bibliotecas públicas y sitios de redes sociales, ¿una cuestión de visibilidad?”, pp. 285-299. 
Con todos los problemas que conlleva hacer una clasificación de redes, Leiva ${ }^{18}$ distingue varios tipos:

1. Redes sociales horizontales. Se trata de redes sociales generalistas que alojan cualquier tipo de temas: trabajo, ocio, amigos familia. Facebook o Tuenti estarían dentro de este grupo.

2. Redes sociales verticales. Especializadas en un tema concreto, intentan reunir personas en torno a un interés específico. Al contrario de las redes horizontales, que suelen trasladar a Internet relaciones que ya existían fuera previamente, las redes sociales verticales sirven para poner en contacto personas que tienen interés en un tema concreto. Un ejemplo de este tipo de redes es Genviajero, dedicada a viajes.

3. Redes sociales personales. Este tipo de redes son a veces horizontales (Tuenti) y otras, verticales. La clave reside en si el interés de la persona que participa es personal y no busca información o a nuevas personas con fines de tipo profesional.

4. Redes sociales profesionales. En estas redes, las personas participan buscando obtener algún tipo de rendimiento relacionado con su profesión: contactos para realizar ventas, obtener un puesto de trabajo, información sobre un tema determinado, etc. Un ejemplo de este tipo de redes lo constituye LinkedIn.

5. Redes sociales híbridas. Las redes sociales pueden convertirse en híbridas cuando los usuarios acaban mezclado conexiones de tipo personal con las de tipo personal, es decir, en una red de tipo profesional se puede acabar intercambiando con algún contacto, información de tipo personal como, por ejemplo, aficiones culinarias, etc.

18 J. Leiva, Redes sociales. Situación y tendencias en relación a la Información y a la Documentación. 
En el ámbito de las bibliotecas universitarias, merecen una especial mención las redes sociales científicas, ${ }^{19}$ redes en las que participan investigadores como, por ejemplo Academia o la ya mencionada LinkedIn, a través de las cuales se puede compartir información, recursos, desarrollar discusiones, etc. En estos casos, la biblioteca puede cumplir un importante papel dando a conocer este tipo de redes, o formando a los usuarios para que puedan utilizarlas.

Aunque los datos sobre redes sociales cambian continuamente, ya hemos señalado que el estudio de Herrera Morillas obtuvo un $59.64 \%$ de participación. ${ }^{20}$ Según una encuesta realizada por REBIUN, ${ }^{21}$ este porcentaje se eleva al $88 \% .{ }^{22}$ Casi la totalidad de las bibliotecas que participan en redes sociales lo hacen en Facebook.

Los usos que las bibliotecas suelen darles a las redes sociales son: comunicar información, establecer comunicación y compartir contenidos.

\section{Blogs, weblogs o bitácoras}

Una bitácora es un sitio web periódicamente actualizado que recopila cronológicamente artículos o textos de uno o varios autores, apareciendo primero el más reciente. El nombre de bitácora está basado en los cuadernos de bitácora, cuadernos de viaje que se utilizaban en los viajes marinos para recoger el desarrollo del viaje y sus vicisitudes.

19 REBIUN. Ciencia 2.0: aplicaciones de la web social a la investigación, op. cit.

20 J. L. Herrera Morillas y Castillo Díaz, A., "Bibliotecas universitarias 2.0. El caso de España", op. cit., p. 189.

21 REBIUN. Resumen de resultados: encuesta sobre buenas prácticas en redes sociales de las universidades y centros de investigación.

22 La diferencia entre ambos datos quizá se deba a que la encuesta de REBIUN se haya hecho con posterioridad al estudio de Herrera Morillas y Castillo Díaz. No obstante, no hemos podido constatar este dato, ya que el documento que presenta los resultados de la citada encuesta, carece de fecha. 
Es una de las herramientas más populares en las bibliotecas, en las que tiene múltiples aplicaciones. Margaíx Arnal ${ }^{23}$ recoge los siguientes tipos de blogs:

1. Blogs de noticias, que ofrecen información sobre el centro, noticias y novedades.

2. Blogs temáticos. Frecuentes en las bibliotecas universitarias, ofrecen información sobre un área temática, sobre un tipo de documento, etc.

3. Blogs de talleres y formación de usuarios.

4. Blogs de referencia. Dedicados a recoger información sobre cualquier área temática, recursos de información, etc. Margaix señala que cumplen las funciones de los blogs temáticos, pero sin especialización.

5. Blogs de clubes de lectura. Sirven a sus miembros para comunicarse e intercambiar opiniones sobre las obras leídas.

6. Blogs de recomendación de lecturas. Mediante los mismos, la biblioteca sugiere lecturas a los usuarios.

7. Blogs de marketing. Similares a los de noticias, la biblioteca pretende atraer a usuarios dando a conocer los servicios, etcétera.

8. Blogs para construir comunidad. Destinados a la participación de los usuarios para crear una comunidad en torno a la biblioteca y su sitio web.

9. Blogs de uso interno. Destinados a fomentar la comunicación entre el personal.

Como se ha señalado, el blog es el tercer recurso más extendido en las bibliotecas universitarias españolas (57.89\%). Se utiliza fundamentalmente como apoyo a los servicios bibliotecarios, para informar sobre novedades y noticias, fomentar la participación de los usuarios y para la comunicación interna entre el personal de la biblioteca. En general, como rasgos característicos presentan los si-

23 D. Margaix Arnal, Informe APEI sobre social, op. cit., p. 14. 
guientes: las bibliotecas universitarias suelen disponer de más de un blog, enlazan con la página web de la biblioteca, tienen archivos, RSS de las entradas y comentarios; las entradas se pueden recuperar por temas, categorías, fecha y palabras clave, hay fechas en los posts, las entradas archivadas superan un año, los últimos posts tienen una antigüedad de dos días, e incluyen enlaces a recursos relevantes y otros blogs similares. ${ }^{24}$

\section{RSS}

Siglas correspondientes a las palabras: Really Simple Syndication. Ha sido definido como:

Formato que permite a los usuarios recibir actualizaciones de contenidos. El RSS es parte de la familia de formatos XML, que ha sido desarrollada para aquellos sitios que se actualizan con frecuencia y que permiten compartir la información y usarla en otros sitios web o programas. Gracias a los agregadores o lectores de feeds (los programas que permiten leer fuentes web), un usuario puede recibir resúmenes de todos los sitios que le interesan en el escritorio de su sistema operativo, en su programa de correo electrónico o mediante otras aplicaciones web. ${ }^{25}$

Esta técnica permite recibir información, al modo de un servicio de Difusión Selectiva de la Información (DSI). ${ }^{26}$

En las bibliotecas universitarias se utiliza principalmente para difundir noticias, eventos de la biblioteca y novedades del catálogo. En cuanto al formato, suelen permitir la búsqueda de noticias,

24 J. L. Herrera Morillas y Castillo Díaz, A. "Bibliotecas universitarias 2.0. El caso de España”, op. cit., pp. 191-192.

25 F. Monsoriu, Diccionario 2.0, p. 122.

26 L. P. Dobrecky, "Hacia la library 2.0: blogs, RSS y wikis", El Profesional de la Información, p. 140. 
incluyen instrucciones de uso y presentan las noticias clasificadas por temas, fecha o título. ${ }^{27}$

\section{Compartir recursos multimedia}

En la web social existen multitud de sitios que permiten compartir objetos digitales como fotografías, videos, presentaciones, etc. Los más conocidos son Flickr, sitio para compartir fotos; YouTube, para compartir vídeos y SlideShare, para compartir presentaciones. Aunque cada sitio tiene sus propias peculiaridades, hay una serie de características comunes: ${ }^{28}$

1. Disponen de una gama de servicios gratuitos, que a veces pueden completarse con otros complementarios que requieren pago por suscripción.

2. Aceptan ficheros en formatos variados.

3. Permiten al usuario establecer contactos, relaciones de seguimiento o de filtrado social.

4. Se pueden establecer distintos niveles de privacidad a la hora de compartir los objetos digitales.

5. Incluyen herramientas para la descripción de contenidos: resúmenes, etiquetas y palabras clave, asignadas por el creador del objeto o los otros usuarios.

6. Los contenidos de estos sitios pueden insertarse en otras páginas web, etc.

7. Ofrecen la posibilidad de aplicar distintos tipos de licencias, fundamentalmente Copyright y Creative Commons.

8. Excepto en el caso de las fotografías, convierten los objetos digitales en objetos flash, consiguiendo una mayor difusión, accesibilidad y una mayor velocidad en la transmisión.

27 J. L. Herrera Morillas y Castillo Díaz, A., "Bibliotecas universitarias 2.0. El caso de España”, op. cit., pp. 192-193.

28 D. Margaix Arnal, Informe APEI sobre social, op. cit., p. 41. 
Las bibliotecas utilizan estos sitios para diversos fines. En el caso de YouTube se ha destacado su utilidad para subir tutoriales ALFIN, los de uso de sus recursos de información, para promocionar la biblioteca, eventos, etc. SlideShare también presta un gran servicio a las bibliotecas posibilitando compartir presentaciones profesionales, como apoyo de actividades relacionadas con la alfabetización en información, etc. ${ }^{29}$

En el ámbito de la investigación, este tipo de servicios resultan de gran interés, ya que los científicos pueden depositar en estos servidores sus archivos, compartirlos con sus equipos de investigación, etc. Además del citado SlideShare, Google Docs constituye otro ejemplo muy popular entre los investigadores.

\section{Mensajería instantánea}

Bajo esta denominación nos referimos al uso del chat, sistema que permite intercambiar tanto mensajes de texto como conversaciones en tiempo real.

El chat es una herramienta muy consolidada en las bibliotecas universitarias, sobre todo, como apoyo de los servicios de referencia virtual, aunque también existen otros chats que se utilizan para orientar sobre otros servicios de la biblioteca.

Por sus especiales características, como las derivadas del contacto directo entre el bibliotecario y el usuario, el uso del chat en las bibliotecas debe estar cuidadosamente reglamentado, ${ }^{30}$ estableciendo: la política de uso (tipo de preguntas que pueden resolverse por este medio); los horarios de atención, claramente publicados; el funcionamiento del servicio en cuanto a aspectos muy variados (confidencialidad; almacenamiento de consultas atendidas; asignación de etiquetas para estudiar las necesidades de información de los usuarios; evaluación del servicio; elaboración de estadísticas,

29 N. González Fernández Villavicencio, "Bibliotecas 2.0 en España: el camino recorrido", op. cit., p. 40.

30 Biblioteca Universidad de Sevilla, "Guía de usos y estilo de la web social en la BUS", op. cit., pp. 13-15. 
etc.); sanciones a los usuarios que no utilicen el servicio de forma respetuosa, etc.

\section{CONCLUSIONES}

La progresiva implantación de aplicaciones o Herramientas 2.0, de la web social o, como se las conoce más recientemente, social media en las bibliotecas universitarias está cambiando la relación entre esta y los usuarios. La comunicación entre ambos es ahora bidireccional y el usuario se ha convertido en un creador de contenidos.

Sin embargo, la implantación de Herramientas 2.0 en las bibliotecas universitarias no cambia su esencia, definida por su principal función, que consiste en apoyar la docencia y la investigación.

El desarrollo de la llamada Biblioteca 2.0 solo tiene sentido si se lleva a cabo con dicha finalidad y si se hace de forma planificada, seleccionando las herramientas más adecuadas, definiendo objetivos claros y si se lleva a cabo una evaluación del rendimiento.

Por otra parte, a pesar de la facilidad de manejo de la mayoría de estas herramientas, su implantación debe ir acompañada de cursos de formación de usuarios, de acuerdo con sus necesidades. Esta formación es más necesaria en el caso de algunos colectivos que, por su edad, no son nativos digitales.

\section{BIBLIOGRAFÍA}

Arroyo Vázquez, N. (2008), "Bibliotecas públicas y sitios de redes sociales, ¿una cuestión de visibilidad?”. [en línea]. En IV Congreso Nacional de bibliotecas Públicas. BP Bibliotecas Plurales. Madrid: Ministerio de Cultura, 2008, pp. 285-299.Disponible en: <http://travesia.mcu. es/portalnb/jspui/bitstream/10421/485/2/CongresoNa cionalBP_04.pdf $>$. [Fecha de consulta: 7 de marzo de 2014]. 
Datos y cifras del sistema universitario español. Curso 2012-2013 (2012), [en línea]. Madrid: Ministerio de Educación, Cultura y Deporte. Disponible en: < http:// www.mecd.gob.es/dms/mecd/educacion-mecd/areaseducacion/universidades/estadisticas-informes/estadisti cas-informes-documentum/datos-cifras/2012-2013-datos -y-cifras-sistema-universitario-espanol.pdf $>$. [Fecha de consulta: 13 de diciembre de 2013].

González Fernández-Villavicencio, N. "Bibliotecas 2.0 en España: el camino recorrido" (2007), Boletín de la Asociación Andaluza de Bibliotecarios, núm. 86-87, enero-junio, pp. 29-46.

Herrera Morillas, J. L. y Castillo Díaz A. (2011), "Bibliotecas universitarias 2.0. El caso de España" [en línea]. En Investigación Bibliotecológica. Archivonomía, Bibliotecología e Información, vol. 25, núm. 55, pp. 175-200. Disponible en: <http://www.revistas.unam.mx/index. php/ibi/article/view/32861>. [Fecha de consulta: 5 de Marzo de 2014].

Leiva, J. (2009), Redes sociales. Situación y tendencias en relación a la Información y a la Documentación [en línea]. Disponible en: <http://www.slideshare.net/Baratz/ informe-redes-sociales-javier-leiva $>$. [Fecha de consulta: 2 de febrero de 2012].

Margaix Arnal, D. (2007), "Conceptos de Web 2.0 y Biblioteca 2.0: origen, definiciones y retos para las bibliotecas actuales". En El profesional de la información, vol. 16, núm. 2, pp. 95-106.

(2008), Informe APEI sobre social [en línea]. Gijón: Asociación Profesional de Especialistas en Información. Disponible en: <http://eprints.rclis.org/12506/1/ informeapeiwebsocial.pdf $>$. [Fecha de Consulta: 6 de marzo de 2014]. 
Merlo Vega, J. A. (2007), Las tecnologías de la participación en las bibliotecas [en línea]. Disponible en: <http:// eprints.rclis.org/10558/1/tecnoparti.pdf $>$. [Fecha de consulta: 3 de marzo de 2014].

Miller, P. (2005), "Web 2.0: Building a New Library" [en línea]. Ariadne, núm. 45, octubre. Disponible en: <http:// www.ariadne.ac.uk/issue $45 /$ miller/ $>$. [Fecha de consulta 20 de octubre de 2010].

Monsoriu, F. (2010), M. Diccionario 2.0. Madrid: Creaciones Copyright.

REBIUN (2011), III Plan estratégico de REBIUN 2020 [en línea]. Disponible en: < https://pendientedemigracion.ucm.es/ BUCM/intranet/doc18579.pdf>. [Fecha de consulta: 3 de marzo de 2014].

(2012), Ciencia 2.0: aplicaciones de la web social a la investigación [en línea]. Disponible en < http://eprints. rclis.org/3867/1/Ciencia20_rebiun.pdf>. [Fecha de consulta: 6 de marzo de 2014].

Resumen de resultados: encuesta sobre buenas prácticas en redes sociales de las universidades y centros de investigación [en línea]. Disponible en: <http:// www.rebiun.org/documentos/Documents/IIIPE_2020_ LINEA3/IIIPE_Linea3_RESUMEN_Encuesta_buenas\% 20practicas_redes\%20sociales_REBIUN.pdf $>$. [Fecha de consulta: 3 de marzo de 2014].

Serrano Cobos, J. (2007), Web 2.0 en las bibliotecas: el concepto Library 2.0 [en línea]. En: Notas ThinkEPI. Disponible en: <http://www.thinkepi.net/web-20-en-las-biblio tecas-el-concepto-library-20>. [Fecha de consulta: $10 \mathrm{de}$ enero de 2011].

Biblioteca Universidad de Sevilla. (2011), Guía de usos y estilo de la web social en la BUS [en línea]. Disponible en: $<\mathrm{http}$ ///bibliotecasocial.pbworks.com/f/67194912-Guia-deUso-de-la-Web-Social-en-la-BUS-2011.pdf>. [Fecha de consulta: 6 de marzo de 2014]. 


\title{
El perfil del usuario 2.0 de la información audiovisual y textual: análisis y discusión
}

\author{
ISABEL VILLASEÑOR RODRÍGUEZ \\ Universidad Complutense de Madrid \\ JuAn José CAlva González \\ Universidad Nacional Autónoma de México
}

$\mathbf{P}$ or lo expuesto hasta el momento a través de los capítulos anteriores, y como conclusiones obtenidas del proyecto "Usuarios 2.0 de la información audiovisual y textual", resulta difícil definir un perfil único del Usuario 2.0 de la información audiovisual y textual porque podría decirse que existen tantos usuarios como individuos navegando por Internet. A pesar de ello, se pueden destacar algunos rasgos que tienen en común y que, acto seguido, se pueden exponer:

- En primer lugar, cabe decir que el Usuario 2.0 de la información audiovisual y textual responde a las características propias de un nuevo individuo, producto de la actual etapa de modernidad. Se trata del hombre postmoderno, quien tiene un ritmo acelerado de vida, caracterizado, entre otras cosas, por la indiferencia o incapacidad de profundización, el nomadismo o la inclusión en nuevas formas de agrupamientos sociales cotidianos y empáticos y, también, por el consumismo. Un individuo en sintonía con lo que Bauman (2012) ha llamado la "modernidad líquida". 
- Por otra parte y en segundo lugar, se puede decir que este usuario de la información tiene un rasgo definitorio que es el de formar parte de lo que algunos han llamado "Cultura 2.0", que se caracteriza, fundamentalmente, porque se sostiene en una nueva concepción social del ser humano, que tiene que ver con el deseo de compartir, estar informado y comunicarse. Pero no de cualquier forma sino utilizando las nuevas tecnologías de la información, que han llegado a casi todos y permiten desarrollar ese deseo.

- En tercer lugar, el Usuario 2.0 de la información audiovisual y textual utiliza, con mayor o menor destreza y conocimiento, las herramientas propias de la Web 2.0 o web social para compartir contenidos de todo tipo, confiando en los demás y convirtiéndose a su vez en una fuente de información de gran valor para los otros.

- Con base en lo anterior, en cuarto lugar, el Usuario 2.0 de la información audiovisual y textual no sólo es consumidor de información sino, también productor de ella, y con la característica de que siempre está comunicando lo que hace o lo que sabe, cultivando así una inteligencia colectiva manifiestamente democrática donde todos pueden declarar sus opiniones y compartir sus conocimientos.

- En quinto lugar, resulta muy importante el hecho de que forma parte de una o varias comunidades, porque es un ser sociable y se reconoce como individuo en la sociedad, y desea interactuar para satisfacer sus necesidades y compartir un proyecto determinado que constituye la razón de ser de su grupo, utilizando una tecnología que le facilita su propósito (personal o profesional) y actuando en un ámbito que siente como propio y al cual pertenece.

- Como sexto lugar, se puede decir que la Web 2.0, que ha sido adoptada por la comunidad de usuarios (ahora Usuarios 2.0), se introduce rápidamente como medio para acceder a la información académica, producto de la docencia y la investigación, en diferentes ámbitos no sólo a nivel licencia- 
tura y postgrado, sino también en los niveles de educación básica y en media superior.

- Cada vez más se utilizan todas las herramientas de la Web 2.0 para que los alumnos se conviertan en Usuarios $2.0 \mathrm{y}$ tengan acceso a la información en diferentes formatos electrónicos, como videos, textos, multimedia, fotos, etc., y establezcan un vínculo entre la enseñanza en escuelas de un diferente orden, donde la información apoya esta enseñanza, y los servicios que puede brindar la biblioteca para que los usuarios tengan este acceso de forma expedita.

- Asimismo, como octavo lugar, se puede decir que las comunidades de diferente orden, como las indígenas, pueden romper la brecha digital que les impide acceder a la información y no sólo volverse consumidores utilizando esta tecnología, sino también productores de aquella información propia de su comunidad indígena, y mostrarle al mundo (por el alcance de la Internet y la web) su identidad.

A partir de las aportaciones ofrecidas en el presente trabajo, se puede ver que estos rasgos se dan no sólo en usuarios de información de bibliotecas universitarias, sino también en las de contenidos audiovisuales. En ambos contextos se ha experimentado un cambio a partir del uso de herramientas Web $2.0 \mathrm{y}$, también, una adaptación a la nueva situación, y se ha establecido una nueva relación entre los pares que es de carácter bidireccional en cuanto que el usuario no sólo consume sino que también crea.

\section{BIBLIOGRAFÍA}

Bauman, Z. (2012), Modernidad líquida. México: FCE. $13^{\text {a }}$ reimpresión. 
Usuarios 2.0 de la información audiovisual y textual. Instituto de Investigaciones Bibliotecológicas y de la Información/UNAM. La edición consta de 100 ejemplares. Coordinación editorial, Carlos Ceballos Sosa; Revisión especializada, Francisco Xavier González y Ortiz; Cotejo y corrección de pruebas, Zyanya Benavides Reyes; Formación editorial, Mario Ocampo Chávez. Fue impreso en papel cultural de 90 g. en Ediciones del Lirio S. A. de C.V., Azucenas 10, Colonia San Juan Xalpa, Delegación Iztapalapa, México, CDMX. Se terminó de imprimir en el mes de mayo de 2017. 